\title{
Desigualdades econômicas inter-regionais, capacidade tributária e esforço fiscal dos estados da Amazônia (1970-2000): uma abordagem econométrica de fronteira estocástica
}

David Ferreira Carvalho - Prof. e pesquisador do CSE e do NAEA da UFPA e prof. e
pesquisador da UNAMA.
Cléo C. Resque de Oliveira - Prof. e pesquisador da FCE da UFPA.
André Cutrim Carvalho - Eng. de computação e Mestrando em Economia pela UNESP.

Resumo

O objetivo do presente trabalho é, portanto, apresentar uma análise dos efeitos das desigualdades econômicas inter-regionais sobre as desigualdades inter-regionais da arrecadação tributária estadual na esfera do federalismo fiscal. O problema da desigualdade interregional entre as regiões e os estados brasileiros sempre foi o principal foco de atenção dos economistas regionais. Entretanto, são relativamente escassos os estudos e as pesquisas que visam estudar os efeitos das desigualdades econômicas inter-regionais sobre as desigualdades tributárias inter-regionais da arrecadação efetiva e potencial entre os estados federativos brasileiros. Por resolveu-se analisar os resultados da medição da capacidade da arrecadação tributária dos estados brasileiros, com destaque para os estados da região Norte, para os anos de 1970 até 2006. A metodologia utilizada para estimar a capacidade de arrecadação tributária e determinar o esforço fiscal dos governos estaduais foi o modelo econométrico de fronteira estocástica, adaptado para esse fim.

\section{Palavras-chave}

desigualdade econômica inter-regionais; arrecadação tributária; modelo econométrico de fronteira estocástica.

\begin{abstract}
The objective of the present work is, therefore, to present an analysis of the effects of the inter-regional economical inequalities about the interregional inequalities of the state outturn in the sphere of the fiscal federalism. The problem of the regional inequality between the areas and Brazilian states was always the main focus of the regional economists'attention. However, its is relatively scarce the studies and researches that seek to study the effects of the inter-regional economical inequalities on the inter-regional tax inequalities of the collection execute and potential of the brazilian states. For that, the results of the measurement of the capacity of the outturn of the Brazilian states were analysed, with prominence for the states of the North area, for the years of 1970 up to 2006. The methodology used to esteem the capacity outturn and to determine the state governments fiscal effort was the econometric model of stochastic border adapted for this end.
\end{abstract}

\section{Keywords}

inter-regional economical inequality; outturn; the model econometric of stochastic border. 


\section{INTRODUÇÃO}

O problema da desigualdade inter-regional entre as macrorregiões e os estados brasileiros sempre foi o principal foco da atenção dos economistas regionais. Porém, são relativamente escassos os trabalhos que estudaram os efeitos das desigualdades econômicas inter-regionais sobre a arrecadação tributária dos estados da periferia. A diversidade tributária das economias estaduais é uma das principais características do federalismo brasileiro. Apesar de ter havido alguma redução das desigualdades econômicas interregionais nos últimos trinta e cinco anos, as disparidades inter-regionais, resultante das grandes diferenças entre as macrorregiões geoeconômicas do Brasil, continuam sendo o principal problema da federação brasileira.

Como efeito, a estrutura tributária, na qual se sustenta a arrecadação própria de cada unidade federada da região, reflete as diferenças no Brasil entre o padrão das economias de base rural e as economias de base industrial. Nesse sentido, para manter a unidade político-territorial da federação, a União recorre às transferências intergovernamentais para suprir de recursos as unidades subnacionais, sobretudo as da periferia. A Constituição de 1946 inaugurou a transferência constitucional de natureza intergovernamental de parte da receita privativa da União para os entes infranacionais. A Emenda Constitucional n. ${ }^{\circ}$ 5, de 21 de novembro de 1961, fixou em 15\% da arrecadação do imposto de renda a parte da transferência constitucional da União, como forma de auxiliar os tesouros estaduais.

A Emenda n. ${ }^{\circ}$ 18, de 1965, instituiu os denominados fundos de participação dos estados (FPE) e dos municípios (FPM), os quais teriam como fontes o Imposto de Renda (IR) e o Imposto sobre Produtos Industrializados (IPI) da União. Além disso, a Constituição de 1988 conservou e ampliou os fundos de participação dos estados (FPE) e dos municípios (FPM). A partir daí, a União passou a transferir 44\% da arrecadação do IR e do IPI para os fundos de participação, e mais 3\%, que foram destinados aos fundos públicos de investimentos nas regiões do Norte, Nordeste e CentroOeste (AMED; NEGREIROS, 2000).

Dada a baixa capacidade de arrecadação tributária própria dos estados federados da periferia brasileira, as transferências constitucionais passaram a ser mecanismos essenciais para esses estados, o que significou aumento da dependência dos estados federados para com a União. Adicionando-se às transferências constitucionais as transferências nãoconstitucionais feitas pela União, por meio de convênios, para os estados da periferia, fica evidente a dependência financeira deles e, por conseguinte, a falta de autonomia fiscal para bancar investimentos públicos estratégicos em infra-estrutura econômica e social e para atrair investimentos privados, sem recorrer à guerra fiscal.

A Constituição de 1988 estabeleceu uma forma institucional de administração público-territorial no Brasil, cujo princípio básico é a 
descentralização tributária. Depois da reforma constitucional de 1988 que no início teve como principal perdedor de recursos tributários a União -, houve uma reviravolta: a União recuperou a sua perda na partilha do "bolo" tributário com a criação das contribuições sociais, um tipo especial de tributo em cascata sem fato gerador, que não é partilhado com os estados federados. Os estados, principalmente os da extrema periferia de base exportadora de matérias-primas para o exterior, como o caso do Pará, foram os grandes perdedores, não só pelas transferências que fazem aos municípios por força de lei, mas também pela ausência de tributos que assegurem alguma compensação pela exploração predatória dos seus recursos não-renováveis. Na ausência de mecanismos compensatórios para realizar os investimentos públicos em capital social básico, resta aos estados da extrema periferia recorrer à concessão de incentivos fiscais como instrumento de atração de investimento privado, o que implica entrar no "jogo de soma zero" da guerra fiscal interestadual (PRADO, 2006).

A reforma constitucional de 1988 tem sido criticada por haver ampliado em demasia a participação dos entes federados infranacionais nos recursos tributários da União, sem o devido aumento das responsabilidades fiscais e sociais quanto às suas políticas públicas de gastos. Contudo, apesar da importância fiscal das transferências da União para os estados, neste artigo pretende-se avaliar apenas os efeitos das desigualdades econômicas interestaduais sobre a arrecadação tributária dos governos estaduais. Portanto, mesmo reconhecendo a importância da redistribuição vertical dos recursos tributários da União em direção aos estados, o estudo enfatiza as diferenças na capacidade de arrecadação tributária própria dos estados federativos brasileiros, especialmente dos estados que compõem a Amazônia, cuja base tributária está assentada em uma economia de natureza extrativa.

O Programa de Modernização das Administrações Fiscais dos Estados Brasileiros (PNAFE), iniciado em 1997 com recursos financeiros oriundos do Banco Interamericano de Desenvolvimento (BID) e contando com a contrapartida dos estados, tem como objetivo melhorar a eficiência administrativa e a transparência na gestão dos recursos públicos estaduais. O aumento da arrecadação tributária própria e um gasto público de qualidade seriam os resultados mais expressivos esperados por parte das autoridades fiscais (BRASIL, 2006, p. 1-2). Abrangendo os 26 estados da federação brasileira e o Distrito Federal, o PNAFE prevê ações de modernização da administração tributária e financeira, além da implantação de uma cooperação sistemática entre as unidades da federação, privilegiando a reengenharia de procedimentos operacionais e de gestão, a capacitação adequada de todos os funcionários e o emprego das avançadas tecnologias de informação e comunicações (TIC). Os resultados obtidos por esse programa confirmam uma melhoria na 
capacidade administrativa fiscal e financeira das Secretarias da Fazenda dos estados do Norte. Esta é outra razão que nos induziu a estudar o esforço fiscal e a capacidade tributária dos estados da Amazônia.

Formula-se aqui a hipótese de que as diferenças existentes nas arrecadações tributárias dos estados federados brasileiros são determinadas por três fatores básicos: 1) pelas disparidades econômicas inter-regionais, que determinam uma distribuição diferenciada da arrecadação tributária própria, 2) pelas diferenças na base tributária, que dependem da estrutura da base produtiva, e 3) pelas diferenças no grau do esforço fiscal das administrações tributárias dos governos estaduais.

Para dar conta da tarefa a que se propõe, o trabalho foi organizado em três seções, além desta introdução e da conclusão: na primeira, discutese a teoria da distribuição das responsabilidades tributárias e as determinações das desigualdades tributárias regionais no âmbito do federalismo fiscal; na segunda, apresentam-se os resultados da distribuição da arrecadação tributária regional entre os níveis dos governos federal, estadual e municipal entre 1970 e 2006; na terceira, apresenta-se a metodologia para estimar a capacidade tributária potencial das unidades federadas e analisam-se os resultados. Na estimação da capacidade de arrecadação tributária potencial dos governos estaduais, foi utilizado o modelo econométrico de fronteira estocástica, adaptado para fins de determinação do esforço fiscal - dado pela razão entre a arrecadação tributária efetiva e a arrecadação tributária potencial - das unidades federativas do Brasil, com destaque para os estados da região Norte.

\section{TEORIA DA DISTRIBUIÇÃO FEDERATIVA DA TRIBUTAÇÃO}

Os economistas clássicos que começaram a refletir sobre os efeitos das ações do Estado e do sistema tributário sobre a dinâmica de funcionamento da economia tomaram os critérios de eficiência alocativa, distributiva e de estabilidade como as principais atribuições econômicas governamentais (MUSGRAVE; MUSGRAVE, 1980, p. 3-17). A teoria clássica da tributação repousa em dois princípios básicos: neutralidade e equidade. O primeiro refere-se à não interferência nas decisões de alocação de recursos tomadas com base no sistema de preços do mercado. A neutralidade é obtida quando a forma de captação tributária do governo não afeta os preços do mercado. Isso significa que a aplicação do princípio da neutralidade supõe o critério de eficiência de Pareto - no sentido econômico de que uma dada alocação de recursos numa economia é eficiente quando é impossível modificá-la de forma a melhorar a posição do nível de bem-estar de um indivíduo, sem piorar a posição de outro qualquer. Com efeito, dada a alocação de recursos na economia, uma tributação é eficiente quando não consegue alterar os preços relativos do mercado para tornar menos eficientes as decisões dos agentes de forma a provocar uma redução no nível geral de 
bem-estar que poderia ser atingido com os recursos disponíveis. Portanto, a aplicação do princípio da eficiência tributária supõe que a situação vigente no instante anterior à imposição do tributo configure uma solução eficiente no sentido do ótimo de Pareto (RESENDE, 2001, p. 158-170). Mas as "falhas" de mercado por assimetrias de informações podem levar à intervenção governamental, sobretudo quando se leva em conta o objetivo de promoção do crescimento econômico.

Outro critério importante da análise tributária refere-se à produtividade do tributo do ponto de vista de sua contribuição para a receita tributária. Essa contribuição tributária pode ser avaliada com base nos coeficientes de elasticidade da receita tributária em relação à renda para diversas alternativas de tributação. Por exemplo, tributos com baixa produtividade de receita e elevados custos de fiscalização seriam incompatíveis com os requisitos de financiamentos dos encargos governamentais. A excessiva busca pela eficiência do Estado, entretanto, tem dificultado a percepção do real papel do Estado - como agente político - e levou à proposição de princípios abstratos estranhos à sua atuação e à criação de sistemas tributários "ideais", como se eles não sofressem a influência de fatores econômicos, políticos e ideológicos e da correlação das forças políticas e sociais presentes no aparelho do Estado.

O princípio da neutralidade deveria ser completado pela equidade na repartição da carga tributária. Um imposto "ideal" seria aquele que, além de ser neutro do ponto de vista da eficiência econômica, fosse justo socialmente, no sentido de garantir uma melhor distribuição eqüitativa do ônus tributário sobre os indivíduos. O princípio da equidade poderia ser avaliado por duas óticas básicas: o princípio do benefício, que propõe que o ônus da tributação seja repartido entre os indivíduos, de acordo com o beneficio obtido por cada um, derivado da provisão dos bens e serviços produzidos pelo governo; o princípio da capacidade de contribuição, que sugere que a repartição da tributação seja feita com base na capacidade individual de contribuição (GIAMBIAGI; ALÉM, 2000, p. 23-51).

Com a globalização, porém, surgiu uma nova visão das finanças públicas federativas que, sem considerar o princípio da equidade, tem enfatizado - em nome apenas da eficiência alocativa e da competitividade sistêmica - a criação de normas e regulamentos que justificam a montagem de estruturas tributárias que terminam lançando uma parcela substancial do ônus da tributação naqueles entes federados mais fracos. Para preservar a unidade federativa, entretanto, a União busca compensar os estados mais fracos com ações redistributivas, centradas em transferências intergovernamentais, visando mitigar as desigualdades inter-regionais. Todavia, essas ações redistributivas, centradas somente em transferências intergovernamentais, podem provocar desvios de recursos e a ineficiência do sistema tributário federativo (FIORI, 1995, p. 19-36). 
No caso da federação brasileira, além da alta carga tributária e da falta de equidade tributária, um terceiro problema surgiu no ambiente globalizado: a perda de competitividade. De fato, quando os tributos indiretos de uma nação representam, basicamente, impostos sobre o valor adicionado (IVA), a competição internacional de bens e serviços entre países tende a ser realizada em bases tributárias harmônicas e similares, no sentido de que cada país taxa com impostos igualmente os produtos importados e os domésticos, ao mesmo tempo que desonera as exportações para o mercado exterior do peso desses tributos (GIAMBIAGI; ALÉM, 2000, p. 259-260).

Em oposição, quando um país, como o Brasil, tem uma estrutura tributária com forte presença de tributos cumulativos, e não passíveis de desoneração, ele acaba tendo um duplo problema: 1) esses tributos em cascatas "incham" os preços dos bens e serviços, ao contrário do que ocorre nos países que não adotam essa prática; 2) tributos em cascatas produzem reações de fuga de empresas potenciais e causam redução da concorrência entre as empresas estabelecidas, na medida em que as empresas podem passar a adotar, como estratégia de defesa contra o excesso de carga tributária microeconômica, uma política de completa verticalização e horizontalização de toda a cadeia produtiva à qual pertencem, para fugir dos impostos indiretos cumulativos. Isso poderá criar estruturas monopolistas e a queda desses tributos a longo prazo.

O resultado disso é a perda da competição não só no mercado nacional, porque isso torna os produtos domésticos mais caros do que os importados, como também no mercado internacional, porque esses mesmos produtos enfrentam a competição dos países que não adotam a prática de exportação de tributos. Apesar disso, a União tem preferido as contribuições que são um tipo de imposto disfarçado de contribuição social, de fácil arrecadação e não partilhado com os estados e municípios.

\subsection{Federalismo fiscal e partilha tributária}

A palavra "federação" expressa a idéia de união ou pacto geopolítico decorrente da articulação dos estados que formam essa União, que, juntos, constituem um Estado Nacional com soberania no plano internacional e autonomia de poder entre os entes federados. A federação é uma forma de organização territorial de poder geopolítico entre o poder federal e os poderes estaduais e municipais. O pacto federativo consiste, portanto, num conjunto de complexas alianças políticas que são soldadas em grande parte por meio da partilha de recursos tributários e dos fundos públicos (AFFONSO, 1995, p. 57-58). O federalismo fiscal resulta, pois, do pacto federativo fiscal para manter a unidade da federação.

A nação brasileira adota como forma de governo a República Federativa. Apesar de ser inspirada na forma de governo norteamericana, diferentemente deste - criado de baixo para cima, com os 
governos estaduais criando o governo federal -, a Federação Brasileira foi instituída de cima para baixo, por decreto do governo central. Tão logo foi criada a Federação, estabeleceu-se uma grande discussão sobre a partilha das receitas tributárias entre a União e os estados. Duas propostas polarizaram a discussão sobre a questão da partilha: a primeira, defendida por Rui Barbosa, buscava o fortalecimento fiscal-financeiro da União; a segunda, apresentada por Júlio de Castilhos, defendia a autonomia política e o fortalecimento fiscal-financeiro dos EstadosMembros (TORRES, 1961, p. 82).

A Constituição de 1988 criou uma inovadora federação, diferente estruturalmente não só do modelo de federação de 1967, mas também dos modelos federativos em geral, com só dois entes federados: União e estados (MUSGRAVE; MUSGRAVE, 1980, p. 553-559). O novo sistema de federação brasileiro tem como principal característica a constitucionalização de três entes federados autônomos: a União, os estados e os municípios. Tal modelo federativo implica uma partilha dos recursos arrecadados pela União entre os estados e os municípios. O princípio balizador desse federalismo brasileiro foi a descentralização administrativa e fiscal.

O novo federalismo fiscal brasileiro está em processo de consolidação. Contudo, embora as demandas dos estados e municípios pela descentralização das receitas públicas tivessem sido atendidas na Constituição de 1988, essa descentralização tributária não foi acompanhada de uma descentralização dos gastos e das responsabilidades públicas cabíveis aos estados subnacionais, sobretudo quanto à responsabilidade fiscal da aplicação transparente e racional dos recursos tributários disponíveis. Para uma melhor compreensão dos problemas atuais do federalismo fiscal brasileiro, é preciso ter em mente duas características relevantes que deram origem à Constituição da Federação Brasileira de 1988: 1) as grandes disparidades inter-regionais e 2) a forte tradição da política regionalista e municipalista do país (VARSANO, 1996; DAIN, 1997).

Na Constituição de 1988, os municípios foram os grandes beneficiados, não só porque foram reconhecidos como membros da federação, em condições de igualdade com os Estados - quanto a direitos e deveres ditados pelo novo regime federativo -, mas também porque tiveram ampliada tanto sua autonomia fiscal-financeira quanto seu direito de receber os recursos partilhados advindos das transferências intergovernamentais compensatórias, federais e estaduais. A relativa independência dos municípios em relação ao poder público estadual é considerada uma das causas das distorções que acentuam os desequilíbrios inter-regionais horizontais e verticais na partilha da receita tributária nacional, sobretudo porque se tornou mais difícil a negociação de reformas tributárias capazes de acomodar todos os interesses na 
busca de um novo equilíbrio federativo. Ademais, na falta de uma reforma político-partidária, há também o elemento político que causa sérios problemas partidários e éticos em razão do extravagante número de pequenos partidos de aluguel que são usados como mercadorias em várias negociações espúrias nos momentos da formação das alianças políticas para assegurar a governabilidade de um grande partido com poder político (RESENDE, 1995, p. 5-10).

\subsection{Regime federativo e desigualdades tributárias regionais}

Em estruturas tributárias federativas, além da permanente busca dos governos pela melhoria da eficiência alocativa e redistributiva, o sistema tributário deve concentrar-se na definição dos níveis de governo mais capazes de exercer a gestão de diferentes instrumentos tributários. Portanto, o grau de eficiência dos instrumentos tributários de cada ente federado depende da escolha da esfera administrativa mais adequada para a gestão tributária de cada tributo do sistema.

Neste ponto, cabe estabelecer a diferença entre descentralização e federalismo. Embora esses conceitos estejam associados de algum modo, eles não são idênticos, nem são tampouco idênticos os seus efeitos tributários. A descentralização tributária refere-se à transferência de funções administrativas do governo nacional (União) para os governos subnacionais (estados e municípios). Já o federalismo fiscal refere-se apenas à transferência da capacidade tributária do governo federal para os governos estaduais e municipais, muitas vezes, sem uma coordenação central (AGHÓN, 1991, p. 8). Apesar disso, em geral, alguns estudiosos das finanças públicas criticam ou defendem tanto a descentralização quanto o federalismo fiscal com base em argumentos de natureza econômica ou política (NUNES; NUNES, 2000, p. 139-140). Uma estrutura federativa pode ser mais ou menos descentralizada, dependendo das atribuições e dos recursos transferidos do Estado nacional para os estados infranacionais, e isso define o regime federativo.

Em regimes federativos, como o do Brasil, a definição dos instrumentos tributários e dos níveis de governo responsáveis pela gestão e pela administração dos recursos tributários deve cumprir dois requisitos essenciais: 1) a redução das perdas da eficiência pública, mediante a correta escolha dos instrumentos tributários adequados e dos níveis eficientes de governo para administrá-los; 2) a necessidade de assegurar a provisão financeira de recursos às distintas unidades federadas, a partir da partilha constitucional dos recursos tributários de acordo com as atribuições funcionais de cada unidade de governo para o financiamento dos gastos públicos do governo nacional e dos governos subnacionais que, em última instância, são os principais responsáveis diretos pela provisão de bens e serviços públicos às populações estaduais e locais. 
A distribuição da responsabilidade fiscal no sistema federativo é um instrumento importante também na estruturação das relações financeiras entre os níveis de governo - por intermédio das transferências intergovernamentais compulsórias ou não -, por permitir uma melhoria nas ações das políticas públicas. Mas as disparidades econômicas regionais num sistema tributário federativo impedem que todas as unidades de governo subnacionais possam financiar as suas despesas com recursos tributários próprios arrecadados em suas jurisdições. Tal impedimento resulta, às vezes, em tomada de crédito de terceiros, por parte de governos infranacionais, o que gera déficits fiscais que são cobertos por dívidas públicas que afetam a estabilidade macroeconômica, de responsabilidade do governo central (LOPREATO, 2002, p. 193-232).

O padrão de financiamento público de estruturas federativas - que apresentam problemas de desigualdades inter-regionais, como o Brasil repousa não apenas na arrecadação de tributos próprios, mas também em transferências intergovernamentais, como instrumentos de correção dos desequilíbrios inter-regionais tributários das unidades de governo de economias estaduais frágeis do ponto de vista econômico. Porém, sem a devida responsabilidade fiscal dos entes subnacionais, as transferências intergovernamentais podem gerar sérias distorções funcionais e fiscais quanto à boa governança da aplicação dos recursos públicos. Portanto, na ausência de mecanismos transparentes de controle governamental do uso racional dos tributos para financiar os gastos públicos, as transferências intergovernamentais podem tornar-se um mecanismo de financiamento de corrupção e de desperdícios, que permite o repasse dos custos de provisão de bens públicos ao conjunto do sistema federativo.

A distribuição das responsabilidades fiscais e sociais entre os níveis de governo deve, também, considerar a possível mobilidade interjurisdicional das atividades econômicas e dos fatores de produção como possível resposta dos agentes diante de um sistema tributário descentralizado e com autonomia administrativa por ente federativo. Nesse particular, TIEBOUT (1956) afirma que a redução dos efeitos dos impostos sobre a mobilidade interjurisdicional permite a definição dos níveis de governo mais adequados para a gestão pública dos tributos que afetam os fatores e as atividades econômicas. Por isso, TIEBOUT (1956) e também OATES (1972) recomendam que se atribua aos governos locais a responsabilidade fiscal da tributação sobre os fatores imóveis - como o Imposto Predial e Territorial Urbano (IPTU) -, já que nesse nível de jurisdição é bem maior a identificação entre contribuintes e beneficiários dos bens e serviços públicos locais de uso coletivo (RUBINFIELD, 1987). Ora, como a vinculação entre a carga tributária e a provisão governamental de bens e serviços públicos é um fator importante na determinação do grau de eficiência do fornecimento dos bens e serviços públicos, a base tributária dos governos locais deve 
descansar principalmente em impostos sobre a propriedade imobiliária e também na cobrança de taxas e contribuições de melhoria pela utilização dos serviços públicos (COSSÍO, 1998, p. 21).

Em que pese a consistência do argumento a respeito da racionalidade no uso do imposto sobre patrimônio no âmbito dos governos locais, a evidência empírica revela que a medida não tem sido assim tão satisfatória. De fato, a base tributária "legal", relativa às propriedades tributáveis no município - sem levar em conta os fatores institucionais, econômicos e culturais -, impede não só que a parcela efetivamente tributada corresponda à esperada com base na definição legal, com também que o imposto sobre o patrimônio evolua ao longo do tempo, paulatinamente, de acordo com a urbanização e o crescimento econômico do país (RESENDE, 2001, p. 244-246). Por isso, no Brasil, para proporcionar mais arrecadação tributária própria aos governos locais, além do IPTU, a Constituição de 1988 adicionou o Imposto sobre Transmissão de Bens Inter Vivos (ITBI), o Imposto sobre Vendas a Varejo de Combustíveis Líquidos e Gasosos (IVV) e o Imposto sobre Serviços (ISS) como tributos de competência dos municípios.

O reconhecimento de que a mobilidade interjurisdicional implica quase sempre uma resposta factível - num regime tributário federativo descentralizado - sobre os rendimentos dos fatores móveis permite induzir que os tributos mais adequados sobre esses fatores devem ser atribuídos ao governo central do regime federativo (ATKINSON; STIGLITZ, 1980). No caso do Brasil, o governo federal é o responsável pela arrecadação tributária do imposto sobre a renda, do comércio exterior e alguns impostos específicos, como o IPI. Esses impostos requerem certo grau de centralização administrativa que facilita a cobrança do imposto - no caso do IR - ou que afeta as políticas econômicas - o caso dos impostos regulatórios sobre o comércio exterior. Além disso, a União dispõe hoje das Contribuições Sociais.

Um corolário desse reconhecimento administrativo de que os instrumentos tributários sobre os fatores móveis devem ser aplicados em escala nacional, pelo governo federal, é a necessidade de que os instrumentos tributários de natureza redistributiva correspondam também ao governo central, pelo fato de que os objetivos de equidade distributiva podem ser alcançados sem afetar a eficiência alocativa espacial dos recursos na economia com a aplicação de uma tributação de base nacional sobre a renda auferida dos agentes. Ademais, como a dimensão nacional dos benefícios derivados da provisão dos bens e serviços públicos pelo governo federal e a própria natureza coletiva da arrecadação do governo central dificultam a direta identificação dos beneficiários e contribuintes, o financiamento tributário da União - por meio de impostos sobre o rendimento dos agentes econômicos, com base no princípio tributário da capacidade de pagamento - não requer a 
validade do princípio da vinculação entre beneficiário e contribuinte, já que os impostos sobre o rendimento também não afetam a oferta de bens e serviços públicos (PELTZMAN, 1992).

Diferentemente da definição das responsabilidades tributárias governamentais sobre o patrimônio e sobre os rendimentos, os ambíguos critérios de eficiência e de equidade não oferecem uma clara orientação de política tributária, no que se refere aos níveis intermediários dos governos estaduais de um sistema federativo, para a administração dos tributos indiretos no Brasil.(OLIVEIRA, 1995, p. 111-123; QUADROS, 1995, p. 75-89). O princípio da correspondência entre o tamanho da base tributária e o nível do governo estadual responsável pela aplicação e pela coleta da tributação indireta favorece o princípio da descentralização administrativa e fiscal desses impostos indiretos (SHAH, 1992). Como uma maior participação dos recursos tributários próprios da estrutura de financiamento das unidades estaduais é importante para garantir uma provisão eficiente de bens e serviços públicos adaptada às preferências estaduais e como os impostos indiretos constituem uma parte significativa das receitas tributárias estaduais, a descentralização fiscal deveria assegurar a autonomia financeira dos estados.

No entanto, apesar da vantagem da autonomia financeira dos governos estaduais, a aplicação descentralizada da tributação indireta pode gerar distorções dentro do sistema tributário federativo, porque, como umas das principais características do regime federativo é o amplo grau de abertura comercial entre as economias regionais, a possibilidade do estreitamento desse grau de abertura torna possível o repasse do peso do financiamento público estadual para outras regiões, por meio da exportação de impostos. Como conseqüência disso, os bens e serviços públicos podem ser financiados por outras jurisdições, rompendo, assim, a correspondência necessária entre contribuintes e beneficiários, o que levaria a uma provisão ineficiente (excessiva) dos bens e serviços públicos da jurisdição que exporta tributos (COSSÍO, 1998, p. 22).

Ademais, a possibilidade que os governos estaduais têm de criar incentivos fiscais a partir desses impostos indiretos, com o propósito de atrair atividades econômicas para a sua jurisdição, é outro argumento a favor da gestão federal desses impostos indiretos. O uso de incentivos fiscais para atrair investimentos privados de outras regiões pode desencadear uma "guerra fiscal" entre os estados federados (CAVALCANTI; PRADO, 1998, p. 19-39). Convém acrescentar, entretanto, que os incentivos fiscais podem constituir uma condição necessária para a alocação espacial de um empreendimento, quando confrontado com uma alternativa natural, mas não uma condição suficiente para orientar as decisões dos investidores em áreas carentes de externalidades.

De qualquer maneira, na ausência de normas legais que impeçam tal comportamento dos estados subnacionais, o acirramento de uma 
"guerra fiscal" entre as unidades tributárias do mesmo nível pode desencadear uma concorrência predatória, que acabará reduzindo a capacidade tributária desses governos. Afora isso, deveria haver uma sintonia entre os níveis de governo atendo em vista a coerência da política macroeconômica. Daí as propostas de centralização tributária indireta nas reformas fiscais sempre rejeitadas pelos estados. No Brasil, além do ICMS - individualmente a maior fonte de receita tributária indireta do país -, os estados e o Distrito Federal são responsáveis pela arrecadação do Imposto sobre a Transmissão Causa Mortis (ITCM) e do Imposto sobre a Propriedade de Veículos Automotores (IPVA) (RESENDE, 2001).

Como se observa, a distribuição da receita tributária entre as esferas de governo do sistema federativo brasileiro resultou da negociação política realizada à época da elaboração da Constituição de 1988. O problema principal que surgiu, depois da implantação do novo regime tributário, foi a falta de articulação entre os recursos arrecadados e os encargos dos governos, o que tem causado uma deterioração da qualidade da arrecadação tributária e da provisão dos bens e serviços públicos para a população dos estados.

Do tratamento teórico da distribuição das competências tributárias num regime federativo infere-se que as responsabilidades fiscais entre níveis de governo não asseguram a auto-suficiência financeira das unidades estaduais, devido à existência de disparidades econômicas interregionais que dão lugar a uma obtenção diferenciada de recursos tributários e a uma provisão desigual de bens e serviços públicos para a população. Assim, nota-se uma certa incompatibilidade entre a redução das perdas de eficiência e a garantia da autonomia financeira. Esse desencontro é bem maior em regimes federativos caracterizados por grandes disparidades econômicas inter-regionais, como o Brasil, o que permite perceber que a aplicação direta dos princípios básicos da teoria da tributação pode provocar a insuficiência financeira dos estados subnacionais. Em oposição, a igualação das disparidades da capacidade tributária dos governos estaduais tem custos em termos de eficiência, sobretudo na provisão de bens e serviços, já que o uso das transferências intergovernamentais destinadas à igualação dos recursos financeiros entre as esferas de governos pode debilitar o vínculo entre a carga tributária e os benefícios derivados da provisão dos bens e serviços públicos. Pior ainda, o recurso às transferências pode gerar certa acomodação fiscal por parte dos estados subnacionais quanto ao aumento do esforço tributário.

Quanto à distribuição da carga tributária governamental, que é definida de acordo com os benefícios obtidos pela provisão de bens e serviços públicos, o sistema tributário nacional estaria expressando em última análise o preço dos bens e serviços provisionados pelo setor público a seus beneficiários de forma a assegurar que as tomadas de decisões da alocação de recursos públicos leve em consideração a razão 
custos e benefícios (SIQUEIRA; NOGUEIRA; BARBOSA (2004). Essa correspondência entre a carga tributária e a provisão de bens e serviços públicos favorece a responsabilidade fiscal e social dos estados subnacionais. Isso significa, por suposto, que os recursos tributários para financiar os gastos públicos das unidades descentralizadas sejam realmente repassados às suas populações na forma de provisão de bens e serviços públicos (AFONSO, 1986)

Essa correspondência num regime fiscal descentralizado é importante como elemento de racionalização das despesas públicas, porque garante que a população beneficiária tome consciência do nexo existente entre a receita tributária arrecadada e os dispêndios públicos das respectivas esferas governamentais do sistema tributário federativo, o que significa que as organizações não-governamentais e as organizações comunitárias podem exigir dos governos responsabilidade na administração da aplicação dos recursos públicos. Nesse rumo, é possível dizer que a accountability pode ser assegurada, desde que os estados subnacionais tenham a capacidade tributária própria de financiar as suas despesas públicas com os tributos extraídos de suas jurisdições, o que implica a necessidade de um elevado grau de descentralização tributária que garanta a autonomia decisória e a suficiência financeira dos estados subnacionais (KHAIR, 2006).

Não obstante, nem todos concordam com esse tipo de regime tributário. MCKENZIE; STAAF (1978), por exemplo, afirmam que não existe competição entre os governos subnacionais quando o governo nacional centraliza por demais os tributos de uma economia, mas, quando descentraliza excessivamente, é possível um aumento do grau de monopólio dos tributos por parte das esferas governamentais subnacionais. BUCHANAN; BRENNAM; (1977), por sua vez, afirmam que a partilha da receita tributária nacional pelo governo central na forma de transferências é indesejável, porque ela subverte o propósito fundamental do federalismo, que é criar um ambiente institucional competitivo entre as jurisdições. Poderia ser possível também identificar as externalidades de gastos entre os estados ou problemas de cobranças de imposto sobre as exportações entre eles e atentar para o princípio da correspondência fiscal, pelo qual cada despesa marginal deveria ser financiada por tributação própria relacionada à comunidade beneficiada (KEEN, 1977).

Mas essa forma, como já foi comentada, é um modelo "ideal" de regime tributário e, portanto, há que se ter em conta a evolução histórica da tributação e do federalismo fiscal de cada país e o estágio do seu desenvolvimento econômico nacional e regional. No Brasil, no estágio de desenvolvimento econômico em que se encontram as regiões e os estados da periferia, as transferências intergovernamentais são importantes instrumentos compensadores das desigualdades econômicas inter- 
regionais. Mas essas compensações tributárias não devem servir para estimular a acomodação fiscal dos estados federados quanto ao aumento da sua capacidade tributária por meio de esforço fiscal próprio. De fato, como as transferências verticais são geralmente financiadas com parte dos recursos tributários coletados pelo governo federal dos estados mais desenvolvidos do centro e destinados aos estados subdesenvolvidos da periferia - com base em critérios frágeis de equidade -, o aumento das transferências intergovernamentais, ao levar a uma dada situação crítica de acomodação fiscal na busca de receita tributária própria, pode debilitar a relação entre carga tributária e despesas públicas nas subunidades governamentais da periferia (PRADO, 2006).

\section{DESIGUALDADES REGIONAIS E DISTRIBUIÇÃO DO FINANCIAMENTO PÚBLICO}

As origens das desigualdades econômicas inter-regionais - com destaque para a extrema periferia, que é a Amazônia Brasileira - já são por demais conhecidas. Desde o ciclo das drogas do sertão, passando pelo ciclo da borracha e da pecuária incentivada até o atual ciclo da mineração, a região amazônica sempre teve uma base econômica de natureza extrativa (CARVALHO, 2005, 2005a). De fato, com exceção do enclave industrial de importação da Zona Franca de Manaus (ZFM), as economias dos estados nortistas são de base extrativa, seja na forma de enclaves de exportação, seja na forma extrativa de base artesanal.

O desenvolvimento econômico da Amazônia deve implicar não apenas na exploração dos seus recursos naturais, mas na geração de emprego e renda, na preservação ambiental e na integração industrial e agroindustrial ao restante da economia brasileira numa relação de troca complementar.

Nas décadas de 60 e 70 do século XX, o governo militar promoveu a "eutanásia do federalismo", passando por cima dos interesses dos estados federados com a criação da denominada "Amazônia Legal" e com a implantação da "Operação Amazônia", que criou duas agências de desenvolvimento - a Superintendência de Desenvolvimento da Amazônia (SUDAM) e o Banco da Amazônia (BASA) -, responsáveis pelos repasses dos recursos fiscais e financeiros do governo federal para os "pólos de desenvolvimento" do programa POLAMAZÔNIA (CARVALHO, 2005a; OLIVEIRA, 1995). Mas, apesar da criação dos pólos de desenvolvimento, da eutanásia do federalismo formal e de outras iniciativas do governo federal para promover a economia da Amazônia, a região continua padecendo de um atraso econômico secular.

Os brasileiros que habitam na Amazônia receiam que a exploração predatória dos seus recursos naturais possa esgotar as riquezas minerais, florestais, biogenéticas e aquáticas antes do tempo necessário para o 
surgimento de inovações técnicas capazes de promover um aproveitamento econômico melhor desses recursos em bases sustentáveis. O que os brasileiros da Amazônia desejam e lutam para conquistar não é apenas a melhoria do padrão de vida social da população da região; é também uma economia industrial integrada ao parque industrial brasileiro, complementar, com capacidade efetiva de redução das desigualdades intra e inter-regionais. Deve ser ressaltado que a redução das disparidades econômicas regionais significa também a redução das desigualdades sociais.

É esse o grande desafio que a Amazônia representa para o Brasil (CARVALHO, 2005a; MENDES, 1979). No entanto, a natureza desse desafio não pode obscurecer a dimensão e o significado econômico, social, cultural e ambiental que a Amazônia já oferece ao país e que continuará oferecendo no futuro, com a sua biodiversidade incompletamente conhecida e com o maior potencial de água doce do planeta.

A Tabela 1 apresenta a recente evolução e participação do Produto Interno Bruto (PIB) da região Norte no PIB do Brasil. Nota-se que, depois de trinta e cinco anos de intervenção do governo federal na Amazônia, a participação da economia nortista na riqueza gerada no Brasil passou de 2,2\% (1970) para 5,0\% (2005), segundo a última informação do Instituto Brasileiro de Geografia e Estatística (IBGE).

Tabela 1: Evolução e distribuição dos PIB regionais do Brasil:1970-2005.

\begin{tabular}{|c|c|c|c|c|c|c|}
\hline \multirow{2}{*}{ Anos } & \multicolumn{5}{|c|}{ Em valor ( R\$ milhão) } & \multirow{2}{*}{ Brasil } \\
\hline & Norte & Nordeste & Sudeste & Sul & Centro-Oeste & \\
\hline 1970 & 5.674 & 30.711 & 171.969 & 43.842 & 10.158 & 262.352 \\
\hline 1975 & 9.139 & 49.374 & 289.191 & 79.833 & 18.340 & 445.878 \\
\hline 1980 & 23.343 & 83.559 & 435.561 & 118.606 & 37.663 & 698.731 \\
\hline 1985 & 29.441 & 108.152 & 461.270 & 131.132 & 36.855 & 766.850 \\
\hline 1990 & 41.856 & 109.073 & 498.842 & 154.435 & 43.739 & 847.945 \\
\hline 1995 & 45.728 & 126.055 & 579.142 & 176.433 & 58.932 & 986.291 \\
\hline 2000 & 50.650 & 144.135 & 636.394 & 193.534 & 76.542 & 1.101 .255 \\
\hline 2005 & 106.523 & 280.505 & 1.213 .791 & 314.934 & 190.161 & 2.105 .914 \\
\hline Anos & \multicolumn{6}{|c|}{ Em percentagem (\%) } \\
\hline 1970 & 2,2 & 11,7 & 65,5 & 16,7 & 3,9 & 100 \\
\hline 1975 & 2 & 11,1 & 64,9 & 17,9 & 4,1 & 100 \\
\hline 1980 & 3,3 & 12 & 62,3 & 17 & 5,4 & 100 \\
\hline 1985 & 3,8 & 14,1 & 60,2 & 17,1 & 4,8 & 100 \\
\hline 1990 & 4,9 & 12,9 & 58,8 & 18,2 & 5,2 & 100 \\
\hline 1995 & 4,6 & 12,8 & 58,7 & 17,9 & 6 & 100 \\
\hline 2000 & 4,6 & 13,1 & 57,8 & 17,6 & 7 & 100 \\
\hline 2005 & 5 & 13,1 & 55,8 & 16,6 & 8,9 & 100 \\
\hline
\end{tabular}

Fonte: Contas regionais (IBGE).

A distribuição tributária vertical dos recursos arrecadados entre níveis de governo tem sido tema recorrente na discussão dos problemas do federalismo fiscal brasileiro. Nos anos 80, a reforma tributária de 1967 era criticada pela excessiva centralização dos recursos tributários 
pela União. O elevado grau de centralização era considerado o principal responsável pela fragilidade e pela dependência financeira dos estados subnacionais. Atualmente, a reforma constitucional de 1998 é criticada pela profunda descentralização tributária - criou três entes federados e por haver ampliado em demasia a participação dos estados subnacionais na partilha dos tributos da União, sem o correspondente aumento das responsabilidades fiscais e sociais.

As transferências verticais (compulsórias e voluntárias) e sem regras de igualação podem enfraquecer o federalismo fiscal, além de promover a subvaloração dos custos dos bens e serviços públicos, o que pode levar a uma provisão ineficiente, ou seja, excessiva em relação àquela que seria fornecida se os gastos públicos dos estados fossem cobertos por receita tributária autônoma retirada da própria jurisdição (NISKANEN, 1978). Ademais, quando as transferências intergovernamentais do governo federal ultrapassam certos limites, cria-se eventualmente a falsa impressão de que os custos dos bens e serviços podem ser financiados por contribuintes de outras jurisdições (WINNER, 1983).

Ora, como as decisões relativas aos gastos públicos e à arrecadação tributária não são coincidentes, o repasse das transferências intergovernamentais da União - para financiar os gastos públicos dos governos estaduais - pode contribuir para o aumento das despesas públicas estaduais, bem acima da capacidade de arrecadação tributária das unidades receptoras das transferências. Além disso, embora os beneficiários dos bens e serviços públicos não tenham que financiar esse provimento, a parte do financiamento público gerado fora da própria jurisdição dos estados pode desestimular o esforço fiscal de arrecadação de receitas próprias por parte das unidades subnacionais receptoras.

É evidente que a possibilidade de generalização desse tipo de comportamento pode gerar uma disputa política por transferências tributárias com reflexos no sistema federativo fiscal. Diante dessa possibilidade, pode-se supor que a federação brasileira - caracterizada por desigualdades econômicas inter-regionais - reproduza também desequilíbrios fiscais inter-regionais. Isso significa que, na ausência de políticas nacionais de desenvolvimento regionais redutoras das desigualdades inter-regionais, a tendência é o aumento das transferências e a dependência financeira dos estados subnacionais em relação ao governo federal, com a conseqüente perda do grau de autonomia decisória. A Tabela 2 apresenta o volume das transferências intergovernamentais da União para os estados e municípios depois da Constituição de 1988.

Nota-se que, desde 1988, o Fundo de Participação dos Estados (FPE) tem aumentado em proporções menores que o Fundo de Participação dos Municípios (FPM). As perdas tributárias provenientes 
da Lei Kandir para os estados exportadores de matérias-primas e bens intermediários foram compensadas pelo Seguro Receita.

Tabela 2: Transferências intergovernamentais no Brasil: 1988-2002.

\begin{tabular}{|c|c|c|c|c|c|c|c|c|c|}
\hline \multirow{2}{*}{$\begin{array}{l}\text { Fluxos } \\
\text { anuais }\end{array}$} & \multicolumn{5}{|c|}{$\begin{array}{c}\text { União - Transferências (-) aos } \\
\text { estados (em R\$ milhões) }\end{array}$} & \multicolumn{4}{|c|}{$\begin{array}{l}\text { União - Transferências (-) aos } \\
\text { municípios (em R \$ milhões) }\end{array}$} \\
\hline & FPE & FPEx & $\begin{array}{l}\text { Seguro } \\
\text { ICMS }\end{array}$ & $\begin{array}{c}\text { FUNDEF } \\
\text { UNIÃOO }\end{array}$ & Soma & FPM & $\begin{array}{l}\text { Seguro } \\
\text { ICMS }\end{array}$ & \begin{tabular}{|c|} 
FUNDEF \\
UNIÃOO
\end{tabular} & Soma \\
\hline 1988 & 9.602 & 0 & 0 & 0 & 9.602 & 11.629 & 0 & 0 & 11.629 \\
\hline 1992 & 14.472 & 2.808 & 0 & 0 & 17.280 & 15.531 & 0 & 0 & 15.531 \\
\hline 1996 & 19.530 & 3.390 & 899 & 0 & 23.819 & 20.439 & 294 & 0 & 20.733 \\
\hline 2000 & 19.181 & 2.354 & 3.820 & 4.521 & 29.876 & 20.182 & 1.271 & 4.562 & 26.016 \\
\hline 2002 & 22.401 & 2.012 & 3.192 & 4.468 & 32.072 & 23.477 & 1.054 & 5.210 & 29.741 \\
\hline 2006 & 23.897 & 2.029 & 1.057 & 3.720 & 30.712 & 25.018 & 0,35 & 5.710 & 31.077 \\
\hline
\end{tabular}

Fonte: Banco Federativo (BNDES). Valores a preços constantes de 2003: IGP-DI.

Observa-se também que as transferências intergovernamentais não-constitucionais - como o Fundo de Desenvolvimento do Ensino Fundamental e de Valorização do Magistério (FUNDEF) e o Fundo de Participação das Exportações (FPEx) - têm ganhado importância nos últimos anos. De qualquer maneira, apesar da relevância das transferências verticais da União para os estados subnacionais, convém destacar os efeitos das desigualdades econômicas inter-regionais sobre a base tributária dos estados brasileiros e, em particular, sobre a capacidade tributária dos estados da região Norte.

É evidente que a distribuição estadual dos recursos tributários na economia nortista não escapa à influência das desigualdades econômicas inter-regionais. A concentração da riqueza e da renda em certas unidades federativas da economia do centro tem influência sobre a distribuição da receita tributária entre as unidades federadas das economias da periferia.

\subsection{Indicadores de desigualdades inter-regionais}

Apesar da constatação das disparidades inter-regionais - entre as macrorregiões e os estados da federação -, a avaliação dos efeitos das desigualdades socioeconômicas estaduais sobre as bases tributárias dos estados subnacionais raramente tem sido objeto de uma reflexão na discussão dos problemas do federalismo fiscal brasileiro. Sem deixar de reconhecer a grande importância das transferências governamentais, esta seção busca avaliar os efeitos das disparidades econômicas interregionais sobre a distribuição da arrecadação tributária dos estados, com ênfase nos estados do Norte do Brasil. Primeiramente, é bom termos um retrato econômico e social das economias estaduais do país. A Tabela 3 confirma algum avanço econômico - quando medido por indicadores, tais como o PIB e o PIB per capita dos estados brasileiros - e um avanço social quando medido pelo Índice de Desenvolvimento Humano (IDH) (longevidade, educação e renda). 
Tabela 3: Indicadores econômicos e sociais dos estados brasileiros: 1991-2000.

\begin{tabular}{|c|c|c|c|c|c|c|c|c|c|c|c|c|}
\hline \multirow{2}{*}{ Anos } & \multicolumn{3}{|c|}{ IDH } & \multicolumn{3}{|c|}{ Populacão (hab.) } & \multicolumn{3}{|c|}{ PIB (R\$ milhões) } & \multicolumn{3}{|c|}{ PIB per capita (R\$ 1,00$)$} \\
\hline & 1991 & 2000 & $\mathrm{TC} \%$ & 1991 & 2000 & $\mathrm{TC} \%$ & 1991 & 2000 & TC\% & 1991 & 2000 & $\mathrm{TC} \%$ \\
\hline \multicolumn{13}{|c|}{ Regiāo Norte } \\
\hline $\mathrm{AC}$ & 0,62 & 0,70 & 1,20 & 417.718 & 557.526 & 3,00 & 1.148 & 1.703 & 4,00 & 2.749 & 3.054 & 1,00 \\
\hline $\mathrm{AM}$ & 0,66 & 0,71 & 0,70 & 2.103 .243 & 2.812 .557 & 3,00 & 14.429 & 18.873 & 2,70 & 6.860 & 6.710 & $-0,30$ \\
\hline AP & 0,69 & 0,75 & 0,90 & 289.397 & 477.032 & 5,20 & 1.377 & 1.968 & 3,60 & 4.759 & 4.126 & $-1,60$ \\
\hline PA & 0,65 & 0,72 & 0,90 & 4.950 .060 & 6.192 .307 & 2,30 & 17.448 & 18.914 & 0,80 & 3.525 & 3.054 & $-1,50$ \\
\hline RO & 0,66 & 0,74 & 1,20 & 1.132 .692 & 1.379 .787 & 2,00 & 3.610 & 5.625 & 4,50 & 3.187 & 4.077 & 2,50 \\
\hline RR & 0,69 & 0,75 & 0,90 & 217.583 & 324.397 & 4,00 & 804 & 1.117 & 3,30 & 3.693 & 3.442 & $-0,70$ \\
\hline TO & 0,61 & 0,71 & 1,60 & 919.863 & 1.157 .098 & 2,30 & 1.556 & 2.450 & 4,70 & 1.692 & 2.118 & 2,40 \\
\hline \multicolumn{13}{|c|}{ Regiáo Nordeste } \\
\hline $\mathrm{AL}$ & 0,55 & 0,65 & 1,60 & 2.514 .100 & 2.822 .621 & 1,20 & 6.095 & 7.023 & 1,40 & 2.424 & 2.488 & 0,20 \\
\hline BA & 0,59 & 0,69 & 1,60 & 11.867 .991 & 13.070 .250 & 1,00 & 37.693 & 48.197 & 2,50 & 3.176 & 3.688 & 1,50 \\
\hline $\mathrm{CE}$ & 0,59 & 0,70 & 1,60 & 6.366 .647 & 7.430.661 & 1,60 & 15.686 & 20.800 & 2,90 & 2.464 & 2.799 & 1,30 \\
\hline MA & 0,54 & 0,64 & 1,60 & 4.930 .253 & 5.651 .475 & 1,40 & 6.970 & 9.207 & 2,80 & 1.414 & 1.629 & 1,40 \\
\hline $\mathrm{PB}$ & 0,56 & 0,66 & 1,60 & 3.201 .114 & 3.443 .825 & 0,70 & 7.245 & 9.238 & 2,50 & 2.263 & 2.682 & 1,80 \\
\hline $\mathrm{PE}$ & 0,62 & 0,71 & 1,40 & 7.127 .855 & 7.918.344 & 1,10 & 24.757 & 29.127 & 1,60 & 3.473 & 3.678 & 0,50 \\
\hline PI & 0,57 & 0,66 & 1,40 & 2.582 .137 & 2.843 .278 & 1,00 & 3.904 & 5.330 & 3,20 & 1.512 & 1.874 & 2,20 \\
\hline $\mathrm{RN}$ & 0,60 & 0,71 & 1,60 & 2.415 .567 & 2.776 .782 & 1,40 & 6.725 & 9.293 & 3,30 & 2.784 & 3.347 & 1,90 \\
\hline SE & 0,60 & 0,68 & 1,20 & 1.491 .876 & 1.784 .475 & 1,80 & 5.476 & 5.921 & 0,80 & 3.670 & 3.318 & $-1,00$ \\
\hline \multicolumn{13}{|c|}{ Região Sudeste } \\
\hline ES & 0,69 & 0,77 & 1,20 & 2.600 .618 & 3.097 .232 & 1,80 & 14.191 & 21.530 & 4,30 & 5.457 & 6.951 & 2,50 \\
\hline MG & 0,70 & 0,77 & 0,90 & 15.743 .152 & 17.891 .494 & 1,30 & 81.564 & 106.169 & 2,70 & 5.181 & 5.934 & 1,40 \\
\hline RJ & 0,75 & 0,81 & 0,70 & 12.807 .706 & 14.391 .282 & 1,20 & 105.174 & 137.877 & 2,70 & 8.212 & 9.581 & 1,50 \\
\hline SP & 0,78 & 0,82 & 0,50 & 31.588 .925 & 37.032 .403 & 1,60 & 301.996 & 370.819 & 2,10 & 9.560 & 10.013 & 0,50 \\
\hline \multicolumn{13}{|c|}{ Região Sul } \\
\hline PR & 0,71 & 0,79 & 1,20 & 8.448 .713 & 9.563 .458 & 1,30 & 50.327 & 65.969 & 2,70 & 5.957 & 6.898 & 1,40 \\
\hline RS & 0,75 & 0,81 & 0,70 & 9.138 .670 & 10.187 .798 & 1,10 & 66.320 & 85.138 & 2,50 & 7.257 & 8.357 & 1,40 \\
\hline SC & 0,75 & 0,82 & 0,90 & 4.541 .994 & 5.356 .360 & 1,70 & 29.927 & 42.428 & 3,60 & 6.589 & 7.921 & 1,90 \\
\hline \multicolumn{13}{|c|}{ Região Centro-Oeste } \\
\hline$\overline{D F}$ & 0,80 & 0,84 & 0,50 & 1.601 .094 & 2.051 .146 & 2,60 & 19.838 & 29.587 & 4,10 & 12.391 & 14.425 & 1,50 \\
\hline GO & 0,70 & 0,78 & 1,20 & 4.018 .903 & 5.003 .228 & 2,20 & 16.142 & 21.665 & 3,00 & 4.016 & 4.330 & 0,80 \\
\hline MS & 0,72 & 0,78 & 0,90 & 1.780 .373 & 2.078 .001 & 1,60 & 8.470 & 11.861 & 3,40 & 4.758 & 5.708 & 1,80 \\
\hline MT & 0,69 & 0,77 & 1,20 & 2.027 .231 & 2.504 .353 & 2,10 & 7.825 & 13.428 & 5,60 & 3.860 & 5.362 & 3,50 \\
\hline BR & 0,70 & 0,77 & 1,00 & 146.825 .475 & 169.799 .170 & 1,50 & 856.698 & 1.101 .255 & 2,50 & 10.346 & 11.380 & 1,00 \\
\hline
\end{tabular}

Fonte: Contas regionais (IBGE). Valores a preços constantes de 2000: IGP-DI. TC = Taxa de crescimento. 
A Tabela 3 permite observar que, embora os grandes estados da região mantenham a liderança intra-regional quanto ao valor absoluto do PIB e na participação relativa deste no Brasil, há algumas situações interessantes: as taxas de crescimento da população dos estados do Norte são em média superiores às dos estados das outras regiões brasileiras. Tal situação decorre do fato de a Amazônia ser uma região de atração de migrantes de outras regiões do país.

Por isso, embora a taxa de crescimento do PIB dos estados amazônicos, entre 1991 e 2000, tenha ficado acima da média brasileira, a taxa de crescimento do PIB per capita foi negativa na maioria dos estados. O IDH dos estados do Norte, apesar de relativamente melhor do que o dos estados do Nordeste, está abaixo da média brasileira. Esse quadro socioeconômico dos estados brasileiros, e sobretudo dos estados da Amazônia, servirá de "pano de fundo" para balizar a avaliação da distribuição tributária horizontal entre os entes federados, tendo em vista as desigualdades inter-regionais.

\subsection{Centralização tributária e desigualdades inter-regionais}

Apesar da importância da arrecadação tributária na identificação dos desequilíbrios fiscais do sistema federativo nacional, a avaliação do grau de centralização como o principal determinante do regime federativo tem limitações. De fato, a participação das esferas de governo na arrecadação global é determinada não somente pela atribuição das competências tributárias entre os níveis de governo, mas também pela composição da carga tributária e pela distribuição inter-regional das bases tributárias. No federalismo fiscal brasileiro, as responsabilidades tributárias para as esferas de governo são definidas pela Constituição. Nesse sentido, não se pode afirmar que as prescrições das duas últimas constituições brasileiras - reformas constitucionais de 1967 e 1988 tiveram um forte conteúdo centralizador ou descentralizador.

$\mathrm{Na}$ verdade, as reformas tributárias, como produto das forças econômicas e políticas em movimento, apenas respondem - em momentos históricos distintos - à adequação, não só a modelos de desenvolvimento diferentes, como também à distribuição racional e eficiente dos instrumentos fiscais entre níveis de governo diferentes (COSSÍO, 1998, p. 28). Por isso, além do perfil do regime tributário de uma federação, a evolução da distribuição da carga de tributos numa federação pode captar um maior ou menor grau de concentração dos recursos tributários em poder da União. No Brasil, depois da estabilização da economia proporcionada pelo Plano Real, a evolução da arrecadação tributária dos estados teve melhor performance, como pode ser visto na Tabela 4.

No entanto, apenas a evolução da arrecadação tributária não explica se esse aumento ocorreu como mera conseqüência do fim do imposto inflacionário ou de alguma mudança na base produtiva por efeito da 
retomada do desenvolvimento econômico. Nesse particular, torna-se necessário analisar outro aspecto associado à questão da capacidade da arrecadação tributária dos estados. Há ainda outro deslize cometido: o nível de agregação usado para a determinação da carga tributária é tão elevado que pode levar a generalizações inadequadas sobre a dinâmica tributária das esferas dos governos subnacionais e da União. Na verdade, as disparidades inter-regionais da capacidade tributária - resultante de bases econômicas diferenciadas - é outra limitação para as análises da evolução do grau de centralização tributária de um regime federativo.

Tabela 4: Evolução da arrecadação tributária estadual no Brasil: 19902005.

\begin{tabular}{c|c|c|c|c|c|c|c|cc}
\hline Estado & 1990 & 1995 & 2000 & 2005 & Estado & 1990 & 1995 & 2000 & 2005 \\
\hline AC & 100 & 124 & 224 & 421 & PB & 100 & 118 & 154 & 178 \\
AL & 100 & 97 & 118 & 150 & PE & 100 & 100 & 117 & 142 \\
AM & 100 & 140 & 103 & 129 & PI & 100 & 130 & 158 & 202 \\
AP & 100 & 179 & 257 & 402 & PR & 100 & 74 & 82 & 136 \\
BA & 100 & 134 & 154 & 169 & RJ & 100 & 107 & 123 & 133 \\
CE & 100 & 121 & 153 & 154 & RN & 100 & 113 & 194 & 244 \\
DF & 100 & 137 & 191 & 258 & RO & 100 & 85 & 137 & 197 \\
ES & 100 & 151 & 153 & 204 & RR & 100 & 120 & 236 & 258 \\
GO & 100 & 97 & 115 & 140 & RS & 100 & 101 & 108 & 125 \\
MA & 100 & 116 & 138 & 193 & SC & 100 & 104 & 111 & 140 \\
MG & 100 & 112 & 122 & 147 & SE & 100 & 109 & 134 & 170 \\
MS & 100 & 90 & 106 & 148 & SP & 100 & 105 & 111 & 107 \\
MT & 100 & 117 & 152 & 196 & TO & 100 & 129 & 201 & 280 \\
PA & 100 & 102 & 123 & 174 & Total & 100 & 107 & 118 & 133 \\
\hline
\end{tabular}

Fonte: Ministério da Fazenda (MF), Secretaria do Tesouro Nacional (STN).

O grau de centralização tributária da federação brasileira varia por estado subnacional, e essa variação está associada às desigualdades interregionais da base produtiva, a qual depende do grau de desenvolvimento econômico de cada estado. É a diversidade econômica inter e intra-regional da economia brasileira - característica, por sinal, positiva e merecedora de outro olhar por parte dos planejadores - que determina, em última análise, a distribuição tributária. Com freqüência, o grau de centralização é determinado pela média nacional da participação relativa da União na arrecadação tributária nacional, o que, por certo, acaba refletindo as tendências da participação tributária dos estados.

A Tabela 5 revela que os recursos tributários arrecadados no Brasil estão concentrados na União, que teve sua participação relativa ampliada de 70,38\% para 71,10\%, entre 2000 e 2006, devido à importância das contribuições sociais e econômicas criadas pelo governo federal. Enquanto isso, os estados-membros tiveram sua participação reduzida de 26,18\% para 25,17\%, e os municípios ampliaram de 3,45\% para 3,73\%.

Contudo, essa forma de medir a centralização da arrecadação tributária, embora possa ser usada para fins de medição da concentração tributária entre os entes de uma federação, não permite a identificação 
das causas que determinam a própria centralização tributária, porquanto esse método pressupõe implicitamente uma participação homogênea nos recursos tributários arrecadados pelas distintas unidades federadas (COSSÍO, 1998, p. 40-41). Em razão disso, resolveu-se medir o grau de centralização tributária por meio das cargas tributárias das esferas de governos da federação brasileira. A hipótese por trás dessa medição é a de que o grau de centralização da tributação nacional está associado às diferenças na carga tributária por nível de governo nas várias unidades federativas e à concentração regional das próprias bases tributárias.

Tabela 5: Distribuição da receita tributária por nível de competência fiscal no Brasil: 2000-2006.

Em R\$ milhões.

\begin{tabular}{l|rrrrr|r|r|rr}
\hline \multirow{2}{*}{ Ano } & \multicolumn{2}{|c|}{2000} & \multicolumn{2}{c|}{2002} & \multicolumn{2}{c|}{2004} & \multicolumn{2}{c}{2006} \\
\cline { 2 - 9 } & \multicolumn{1}{c|}{ Valor } & \multicolumn{1}{c}{$\%$} & \multicolumn{1}{c}{ Valor } & \multicolumn{1}{c}{$\%$} & \multicolumn{1}{c}{ Valor } & \multicolumn{1}{c}{$\%$} & \multicolumn{1}{c}{ Valor } & \multicolumn{1}{c}{$\%$} \\
\hline União & 236.317 & 70,38 & 319.704 & 71,29 & 419.570 & 71,29 & 522.620 & 71,1 \\
\hline \multicolumn{1}{c}{ Impostos } & 90.390 & 26,92 & 122.489 & 27,31 & 146.795 & 24,94 & 182.035 & 24,76 \\
\hline IR & 59.916 & 17,84 & 90.673 & 20,22 & 109.622 & 18,63 & 136.840 & 18,62 \\
IPI & 18.699 & 5,57 & 19.659 & 4,38 & 22.538 & 3,83 & 28.224 & 3,84 \\
IOF & 3.096 & 0,92 & 3.996 & 0,89 & 5.209 & 0,89 & 6.734 & 0,92 \\
ICE & 8.445 & 2,51 & 7.970 & 1,78 & 9.181 & 1,56 & 9.934 & 1,35 \\
ITR & 234 & 0,07 & 191 & 0,04 & 245 & 0,04 & 302 & 0,04 \\
\hline Contribuíções & 145.927 & 43,46 & 197.215 & 43,98 & 272.775 & 46,35 & 340.585 & 46,33 \\
\hline CPPS & 55.715 & 16,59 & 71.028 & 15,84 & 93.765 & 15,93 & 123.520 & 16,8 \\
COFINS & 38.707 & 11,53 & 50.913 & 11,35 & 77.593 & 13,18 & 90.585 & 12,32 \\
CPMF & 14.395 & 4,29 & 20.265 & 4,52 & 26.340 & 4,48 & 32.058 & 4,36 \\
CSLL & 8.750 & 2,61 & 12.507 & 2,79 & 19.575 & 3,33 & 25.841 & 3,52 \\
PIS & 8.339 & 2,48 & 11.219 & 2,5 & 17.116 & 2,91 & 20.016 & 2,72 \\
PASEP & 1.312 & 0,39 & 1.278 & 0,28 & 2.301 & 0,39 & 3.579 & 0,49 \\
FGTS & 18.709 & 5,57 & 22.422 & 5 & 28.269 & 4,8 & 36.505 & 4,97 \\
CIDE & 0 & 0 & 7.583 & 1,69 & 7.816 & 1,33 & 8.481 & 1,15 \\
\hline Estados & 87.902 & 26,18 & 112.922 & 25,18 & 147.895 & 25,13 & 185.028 & 25,17 \\
\hline ICMS & 82.279 & 24,5 & 105.386 & 23,5 & 138.275 & 23,5 & 171.669 & 23,35 \\
IPVA & 5.294 & 1,58 & 7.017 & 1,56 & 8.910 & 1,51 & 12.419 & 1,69 \\
ITCD & 329 & 0,1 & 519 & 0,12 & 710 & 0,12 & 941 & 0,13 \\
\hline Municípios & 11.575 & 3,45 & 15.809 & 3,53 & 21.054 & 3,58 & 27.405 & 3,73 \\
\hline ISS & 6.106 & 1,82 & 7.886 & 1,76 & 10.844 & 1,84 & 15.327 & 2,09 \\
IPTU & 4.519 & 1,35 & 6.501 & 1,45 & 8.602 & 1,46 & 9.943 & 1,35 \\
ITBI & 950 & 0,28 & 1.422 & 0,32 & 1.608 & 0,27 & 2.134 & 0,29 \\
\hline Total & 335.794 & 100 & 448.435 & 100 & 588.519 & 100 & 735.052 & 100 \\
\hline
\end{tabular}

Fonte: MF, STN.

A Tabela 6 mostra a evolução da carga tributária dos três níveis de competência fiscal. Nota-se que a atribuição das competências tributárias no Brasil é compatível com os fundamentos da teoria do federalismo fiscal: os impostos sobre renda correspondem à União, a tributação sobre o patrimônio é atribuída aos governos locais e a tributação sobre a produção e comercialização é de competência dos estados federados Contudo, uma análise mais meticulosa mostra exceções, como os casos do IPI e do Imposto sobre a Propriedade Territorial Rural (ITR), que estão na esfera de competência do governo federal, e o ISS municipal, que não segue as recomendações da teoria do federalismo fiscal. 
Tabela 6: Carga tributária por níveis de competência fiscal dos governos no Brasil: 2000-2006.

Em R\$ milhões.

\begin{tabular}{|c|c|c|c|c|c|c|c|c|}
\hline \multirow{2}{*}{ Entes federados } & \multicolumn{2}{|c|}{2000} & \multicolumn{2}{|c|}{2002} & \multicolumn{2}{|c|}{2004} & \multicolumn{2}{|c|}{2006} \\
\hline & Valor & $\%$ PIB & Valor & $\%$ PIB & \begin{tabular}{l|l|} 
Valor \\
\end{tabular} & $\%$ PIB & \begin{tabular}{l|l} 
Valor \\
\end{tabular} & $\%$ PIB \\
\hline União & 236.317 & 21,46 & 319.704 & 23,75 & 419.570 & 23,75 & 522.620 & 22,5 \\
\hline Impostos & 90.390 & 8,21 & 122.489 & 9,1 & 146.795 & 8,31 & 182.035 & 7,84 \\
\hline IR & 59.916 & 5,44 & 90.673 & 6,74 & 109.622 & 6,21 & 136.840 & 5,89 \\
\hline PI & 18.699 & 1,7 & 19.659 & 1,46 & 22.538 & 1,28 & 28.224 & 1,22 \\
\hline & 3.096 & 0,28 & 3.996 & 0,3 & 5.209 & 0,29 & 6.734 & 0,29 \\
\hline CE & 8.445 & 0,77 & 7.970 & 0,59 & 9.181 & 0,52 & 9.934 & 0,43 \\
\hline ITR & 234 & 0,02 & 191 & 0,01 & 245 & 0,01 & 302 & 0,01 \\
\hline Contribuiçōes & 145.927 & 13,25 & 197.215 & 14,65 & 272.775 & 15,44 & 340.585 & 14,66 \\
\hline CPPS & 55.715 & 5,06 & 71.028 & 5,28 & 93.765 & 5,31 & 123.520 & 5,32 \\
\hline & .707 & 3,51 & .913 & 3,78 & 77.593 & 4,39 & 90.585 & 3,9 \\
\hline CPMF & 14.395 & 1,31 & 20.265 & 1,51 & 26.340 & 1,49 & 32.058 & 1,38 \\
\hline CSLL & 8.750 & 0,79 & 12.507 & 0,93 & 19.575 & 1,11 & 25.841 & 1,11 \\
\hline & 8.339 & 0,76 & 11.219 & 0,83 & 17.116 & 0,97 & 20.016 & 0,86 \\
\hline & 1.312 & 0,12 & 1.278 & 0,09 & 2.301 & 0,13 & 3.579 & 0,15 \\
\hline $\mathrm{G}^{-1}$ & 18.709 & 1,7 & 22.422 & 1,67 & 28.269 & 1,6 & 36.505 & 1,57 \\
\hline & 0 & 0 & & 0,56 & 7.816 & 0,44 & 8.481 & 0,37 \\
\hline Estados & 87.902 & 7,98 & 112.922 & 8,39 & 147.895 & 8,37 & 185.028 & 7,97 \\
\hline CMS & .279 & & 105.3 & 7,8 & 138.275 & 7,8 & 171.669 & 7,39 \\
\hline & 5.294 & 0,48 & 7.017 & 0,52 & 8.910 & 0 & 12.419 & 0,53 \\
\hline ITC & 329 & 0,03 & 519 & 0,04 & 710 & 0,04 & 941 & 0,04 \\
\hline Municipios & 11.575 & 1, & 15.809 & 1,17 & 21.054 & 1,19 & 27.405 & 1,18 \\
\hline ISS & & & 7.886 & 0,5 & 10.844 & 0,6 & 15.327 & 0,66 \\
\hline $\mathrm{P} \mid$ & 4.519 & 0,41 & 6.501 & 0,48 & 8.602 & 0.49 & 9.943 & 0,43 \\
\hline IT] & 950 & 0,09 & 1.422 & 0,11 & 1.608 & 0,09 & 2.134 & 0,09 \\
\hline PIB & 1.101 & 255 & 1.346 . & 28 & 1.766. & 521 & 2.322 . & 818 \\
\hline Carga tr & 30, & & 33,3 & & 33,3 & & 31,6 & \\
\hline Carga trib. bruta & 32, & & 35,6 & & 35,7 & & 34,2 & \\
\hline
\end{tabular}

Fonte: MF, STN.

Nota-se também que a União teve a sua carga tributária ampliada com a inclusão dos recursos tributários oriundos das contribuições sociais, econômicas e previdenciárias. A Tabela 6 permite observar que, entre 2000 e 2006, a carga tributária e a carga tributária bruta - que incorpora as taxas, os emolumentos e outras contribuições - apresenta uma suave tendência de queda, provavelmente devido à retomada do crescimento da economia brasileira. Nesse período, a carga tributária caiu de 33,31\% para 31,64\%, e a carga tributária bruta, de 35,76\% para 34,23\%. Mesmo assim, ainda é alta a carga tributária bruta brasileira.

O aumento da carga tributária da União deve-se, principalmente, ao aumento das contribuições sociais, que mais do que compensaram a queda da carga dos impostos federais, como revela a Tabela 6. Esse fato, sem dúvida, tem contribuído para acentuar mais a tendência de centralização tributária da União, tendência que foi combatida pelas forças da tradição na Constituição de 1988. Por outro lado, as contribuições sociais e econômicas são tributos indiretos cumulativos que aumentam a pressão tributária sobre todas as atividades econômicas formais, e isso, por sua vez, acaba afetando a competitividade das empresas brasileiras. Não obstante, a carga tributária dos estados brasileiros declinou de 8,37\% para 7,97\%, entre 2004 e 2006, talvez devido à retomada do crescimento econômico e aos incentivos fiscais 
concedidos num ambiente de guerra fiscal. De fato, o ICMS é o principal imposto sobre comercialização dos bens do país. Contudo, a utilização desse imposto como instrumento de atração de investimentos, por meio de concessão de incentivos fiscais, tem causado perda de recursos, que tenderá a aumentar se continuar a guerra fiscal entre os estados.

\subsection{Distribuição regional da arrecadação tributária por esferas de governo}

A Tabela 7 revela a heterogeneidade intra e inter-regional da receita tributária global, federal e estadual por região e por estados da federação brasileira. Entre 2000 e 2005, a receita tributária global da região Sudeste declinou de 51,84\% (2000) para 51,07\% (2005), enquanto isso, a receita tributária global das outras regiões brasileiras aumentou. No caso da região Norte, houve um aumento da receita tributária global de 3,38\% (2000) para 4,01\% (2005), com destaque para os estados do Amazonas e Pará, que tiveram suas participações ampliadas em 18,5\% e 19,0\%, respectivamente.

Tabela 7: Distribuição da receita tributária por região e por estados do Brasil: 2000-2005.

\begin{tabular}{|c|c|c|c|c|c|c|}
\hline \multirow{2}{*}{$\begin{array}{l}\text { Região e } \\
\text { Estados }\end{array}$} & \multicolumn{3}{|c|}{2000} & \multicolumn{3}{|c|}{2005} \\
\hline & Global & Federal & Estadual & Global & Federal & Estadual \\
\hline Norte & 3,38 & 1,66 & 5,65 & 4,01 & 1,57 & 7,11 \\
\hline$\overline{A C}$ & 0,22 & 0,04 & 0,47 & 0,25 & 0,03 & $\overline{0,57}$ \\
\hline AM & 1,08 & 0,90 & 1,44 & 1,28 & 0,93 & 1,78 \\
\hline $\mathrm{AP}$ & 0,19 & 0,05 & 0,39 & 0,24 & 0,04 & 0,55 \\
\hline PA & 1,00 & 0,45 & 1,70 & 1,19 & 0,39 & 2,03 \\
\hline RO & 0,40 & 0,13 & 0,67 & 0,45 & 0,10 & 0,89 \\
\hline RR & 0,17 & 0,04 & 0,34 & 0,19 & 0,02 & 0,40 \\
\hline TO & 0,33 & 0,05 & 0,65 & 0,42 & 0,06 & 0,89 \\
\hline Nordeste & 10,18 & 4,78 & 14,34 & 11,10 & 4,59 & 17,48 \\
\hline $\mathrm{AL}$ & 0,60 & 0,19 & 0,89 & 0,61 & 0,12 & 0,99 \\
\hline BA & 2,98 & 1,75 & 3,73 & 3,13 & 1,74 & 4,81 \\
\hline $\mathrm{CE}$ & 1,58 & 0,75 & 2,15 & 1,64 & 0,74 & 2,34 \\
\hline MA & 0,83 & 0,24 & 1,31 & 0,95 & 0,32 & 1,55 \\
\hline $\mathrm{PB}$ & 0,78 & 0,31 & 1,16 & 0,74 & 0,20 & 1,27 \\
\hline PE & 1,77 & 1,13 & 2,31 & 2,16 & 1,03 & 3,20 \\
\hline PI & 0,47 & 0,16 & 0,76 & 0,56 & 0,10 & 0,95 \\
\hline $\mathrm{RN}$ & 0,71 & 0,24 & 1,14 & 0,76 & 0,19 & 1,33 \\
\hline SE & 0,45 & 0,02 & 0,88 & 0,56 & 0,15 & 1,04 \\
\hline Sudeste & 51,84 & 57,98 & 45,77 & 51,07 & 57,84 & 43,85 \\
\hline ES & 1,58 & 1,29 & 1,90 & 1,82 & 1,46 & 2,42 \\
\hline MG & 6,54 & 4,33 & 7,89 & 6,58 & 4,38 & 8,55 \\
\hline RJ & 11,52 & 13,70 & 9,72 & 13,69 & 18,46 & 9,39 \\
\hline SP & 32,20 & 38,66 & 26,26 & 28,97 & 33,55 & 23,49 \\
\hline Sul & 19,30 & 26,81 & 12,11 & 17,59 & 26,95 & 13,33 \\
\hline PR & 4,35 & 3,89 & 4,03 & 4,18 & 3,34 & 4,59 \\
\hline RS & 4,93 & 3,99 & 5,45 & 4,91 & 3,89 & 5,70 \\
\hline SC & 2,28 & 1,61 & 2,62 & 2,56 & 1,84 & 3,04 \\
\hline Centro-Oeste & 7,70 & 8,76 & 7,98 & 8,03 & 9,05 & 8,07 \\
\hline DF & 10,97 & 7,45 & $\overline{3,52}$ & 10,30 & 7,97 & 2,33 \\
\hline GO & 1,49 & 0,80 & 1,91 & 1,60 & 0,58 & 2,57 \\
\hline MS & 0,75 & 0,30 & 1,13 & 0,83 & 0,28 & 1,32 \\
\hline MT & 0,86 & 0,21 & 1,42 & 0,95 & 0,22 & 1,84 \\
\hline Brasil & 100 & 100 & 100 & 100 & 100 & 100 \\
\hline
\end{tabular}

Fonte: MF, STN e Secretaria da Receita Federal (SRF). 
A arrecadação tributária federal da região Sudeste teve a sua participação reduzida de 57,98\% (2000) para 57,84\% (2005). No caso da região Norte, a arrecadação dos tributos federais caiu de 1,66\% (2000) para 1,57\% (2005). Entre 2000 e 2005, a participação dos tributos estaduais da região Sudeste declinou de 45,77\% (2000) para 43,85\% (2005), como resultado do avanço das outras regiões. No caso específico da região Norte, a participação da receita tributária estadual subiu de 5,65\% (2000) para 7,11\% (2005), com destaque para os estados do Amazonas e Pará.

Tabela 8: Carga tributária por região e por estados do Brasil: 20002005.

\begin{tabular}{|c|c|c|c|c|c|c|}
\hline \multirow{2}{*}{$\begin{array}{c}\text { Região e } \\
\text { Estados }\end{array}$} & \multicolumn{3}{|c|}{2000} & \multicolumn{3}{|c|}{2005} \\
\hline & Global & Federal & Estadual & Global & Federal & Estadual \\
\hline Norte & 1,41 & 0,17 & 0,47 & 1,64 & 0,31 & 1,00 \\
\hline$\overline{\mathrm{AC}}$ & 0,09 & 0,00 & 0,04 & 0,10 & 0,01 & 0,08 \\
\hline AM & 0,45 & 0,09 & 0,12 & 0,52 & 0,18 & 0,25 \\
\hline $\mathrm{AP}$ & 0,08 & 0,01 & 0,03 & 0,10 & 0,01 & 0,08 \\
\hline PA & 0,42 & 0,05 & 0,14 & 0,49 & 0,08 & 0,29 \\
\hline RO & 0,17 & 0,01 & 0,06 & 0,18 & 0,02 & 0,13 \\
\hline RR & 0,07 & 0,00 & 0,03 & 0,08 & 0,00 & 0,06 \\
\hline TO & 0,14 & 0,01 & 0,05 & 0,17 & 0,01 & 0,12 \\
\hline Nordeste & 4,24 & 0,49 & 1,18 & 4,55 & 0,91 & 2,45 \\
\hline$\overline{\mathrm{AL}}$ & 0,25 & 0,02 & 0,07 & 0,25 & 0,02 & 0,14 \\
\hline $\mathrm{BA}$ & 1,24 & 0,18 & 0,31 & 1,28 & 0,34 & 0,68 \\
\hline $\mathrm{CE}$ & 0,66 & 0,08 & 0,18 & 0,67 & 0,15 & 0,33 \\
\hline MA & 0,35 & 0,02 & 0,11 & 0,39 & 0,06 & 0,22 \\
\hline PB & 0,33 & 0,03 & 0,10 & 0,30 & 0,04 & 0,18 \\
\hline PE & 0,74 & 0,12 & 0,19 & 0,89 & 0,20 & 0,45 \\
\hline PI & 0,2 & 0,02 & 0,06 & 0,23 & 0,02 & 0,13 \\
\hline RN & 0,3 & 0,02 & 0,09 & 0,31 & 0,04 & 0,19 \\
\hline SE & 0,19 & 0,00 & 0,07 & 0,23 & 0,03 & 0,15 \\
\hline Sudeste & 21,58 & 5,96 & 3,77 & 20,92 & 11,45 & 6,16 \\
\hline ES & 0,66 & 0,13 & 0,16 & 0,75 & 0,29 & 0,34 \\
\hline MG & 2,72 & 0,44 & 0,65 & 2,70 & 0,87 & 1,20 \\
\hline RJ & 4,8 & 1,41 & 0,80 & 5,61 & 3,65 & 1,32 \\
\hline SP & 13,4 & 3,97 & 2,17 & 11,87 & 6,64 & 3,30 \\
\hline Sul & 8,04 & 2,75 & 1,00 & 7,21 & 5,33 & 1,87 \\
\hline$\overline{\mathrm{PR}}$ & 1,81 & 0,40 & 0,33 & 1,71 & 0,66 & 0,64 \\
\hline RS & 2,05 & 0,41 & 0,45 & 2,01 & 0,77 & 0,80 \\
\hline SC & 0,95 & 0,17 & 0,22 & 1,05 & 0,36 & 0,43 \\
\hline Centro-Oeste & 3,21 & 0,90 & 0,66 & 3,29 & 1,79 & 1,13 \\
\hline$\overline{\mathrm{DF}}$ & 1,92 & 0,77 & 0,29 & 1,91 & 1,58 & 0,33 \\
\hline GO & 0,62 & 0,08 & 0,16 & 0,66 & 0,11 & 0,36 \\
\hline MS & 0,31 & 0,03 & 0,09 & 0,34 & 0,06 & 0,19 \\
\hline MT & 0,36 & 0,02 & 0,12 & 0,39 & 0,04 & 0,26 \\
\hline C. tributária & & 32,55 & & & 31,40 & \\
\hline
\end{tabular}

Fonte: MF, STN e SRF.

A Tabela 8 confirma a heterogeneidade intra e inter-regional em termos da carga tributária global, federal e estadual distribuída pelas regiões e pelos estados brasileiros. Entre 2000 e 2005, a carga tributária 
global do Sudeste declinou de 21,58\% (2000) para 20,92\% (2005), enquanto isso a carga tributária global da região Norte teve uma pequena alta de 1,41\% (2000) para 1,64\% (2005). A carga tributária dos tributos federais arrecadados nas regiões e nos estados da federação apresenta uma tendência de alta no período analisado. Quanto à carga tributária estadual da arrecadação própria dos estados, nota-se também uma tendência de alta em todas as regiões e em todos os estados da federação. Como se observa, apesar de ter havido uma pequena redução das disparidades econômicas inter-regionais nas últimas quatro décadas, as diferenças econômicas entre as regiões e os estados da federação continuam sendo acentuadas nos cinco primeiros anos do século XXI.

A distribuição inter-regional dos recursos tributários está de alguma forma associada às desigualdades econômicas inter-regionais. $\mathrm{Na}$ verdade, a concentração das bases produtivas em algumas regiões e em alguns estados explica melhor a distribuição desequilibrada da arrecadação tributária entre as unidades da federação. No caso específico da Amazônia, é bom lembrar que até bem pouco tempo os estados do Acre, Amapá, Rondônia e Roraima eram territórios federais administrados com recursos exclusivamente do governo federal. Isso pode também explicar, em parte, o aumento das transferências intergovernamentais da União para esses estados de base agroextrativa da Amazônia e o apoio político incondicional deles às manobras do governo federal no Congresso.

\section{CAPACIDADE TRIBUTÁRIA E ESFORÇO FISCAL}

A primeira delas é a estrutura tributária vigente na federação quanto à definição da coleção de tributos, suas formas de incidência, esferas de competência, regras de partilha das receitas e outras mais. A segunda é a base tributária das esferas do governo nas unidades federadas, base que depende da capacidade de pagamento dos contribuintes cujas atividades econômicas estão sob sua jurisdição. Os fatores determinantes da base tributária são as próprias estruturas econômicas, sociais e demográficas, com destaque para o produto interno bruto, a renda per capita, a distribuição da renda, a distribuição setorial da produção e o grau de urbanização. Por fim, a terceira dimensão refere-se à eficácia da arrecadação tributária própria de cada ente federado.

As duas primeiras dimensões expressam o potencial de arrecadação tributária na hipótese de uma eficaz gestão fiscal do aparelho tributário. A eficácia do fisco, por sua vez, depende do esforço de arrecadação tributária, dos recursos administrativos e técnicos e da tecnologia computacional. A estrutura tributária desempenha uma função mediadora entre a base tributária vigente e a eficácia da arrecadação, na medida em 
que delimita as condições técnicas e institucionais do potencial fiscal de arrecadação e também estabelece o mecanismo de estímulos e incentivos para impulsionar o esforço tributário das unidades federadas e das esferas de governo da federação (REIS; BLANCO, 1996, p. 14-15).

É possível que parte do aumento da participação da receita tributária dos estados da região Norte, em relação à totalidade da receita tributária brasileira, seja o resultado de alguma mudança em curso na estrutura produtiva da região e da melhoria do esforço fiscal decorrente do programa de modernização da administração fiscal dos estados nortistas inseridos no PNAFE, como mostra a Tabela 9. De qualquer maneira, apesar do processo em curso de mudança da base extrativa para uma base produtiva agroindustrial em certas áreas da Amazônia, sobretudo naquelas em que já se cultiva a soja, cacau, dendê, café, açaí, pupunha e guaraná, ainda assim é muito cedo para tirar conclusões definitivas.

Tabela 9: Resultados do PNAFE nos estados da região Norte. (Em R\$ milhões)

\begin{tabular}{lccccc}
\hline Estados & 1997 & 2002 & $\mathrm{D} \%^{*}$ & $\mathrm{D}^{* *}$ \\
\hline Acre & 51 & 111 & 118 & 64 \\
ICMS & 3 & 6 & 84 & 38 \\
IPVA & 55 & 139 & 152 & 89 \\
Amapá & 4 & 8 & 80 & 35 \\
ICMS & & & & \\
IPVA & 1.225 & 1.938 & 58 & 19 \\
Amazonas & 26 & 40 & 57 & 18 \\
ICMS & & & & \\
IPVA & 769 & 1.689 & 120 & 65 \\
Pará & 40 & 56 & 38 & 4 \\
ICMS & & & & \\
IPVA & 366 & 626 & 71 & 29 \\
Rondônia & 12 & 25 & 116 & 63 \\
ICMS & & & & \\
IPVA & 52 & 124 & 138 & 79 \\
Roraima & 2 & 4 & 113 & 61 \\
ICMS & & & & \\
IPVA & 156 & 416 & 166 & 100 \\
Tocantins & 4 & 16 & 307 & 206 \\
ICMS & &
\end{tabular}

Fonte: Relatório do MF, Unidade de Coordenação de Programas (UCP).

* Variação em valores correntes. ${ }^{* *}$ Variação corrigida pelo IP.

\subsection{Método determinístico de mensuração da capacidade de arrecadação}

A base econômica de uma dada jurisdição federativa define a capacidade de arrecadação potencial que a unidade federativa possui para a obtenção de recursos tributários. Ademais, a alíquota efetiva, o esforço fiscal (mede a eficiência administrativa da instituição responsável pela obtenção da receita tributária), a modalidade do tributo cobrado - 
se imposto cumulativo ou não cumulativo - e o método da incidência princípio da origem, do destino e do crédito fiscal - completam o elenco dos principais fatores que devem ser considerados na estimativa.

A partir da caracterização dessas dimensões, pode-se definir a capacidade tributária potencial de uma unidade da federação como o máximo de arrecadação que o aparelho tributário poderia obter de sua base tributária, dada a estrutura econômica vigente num dado momento do tempo. A razão entre a arrecadação tributária efetiva e a capacidade tributária potencial define a eficácia tributária de uma determinada unidade federada num dado período de tempo considerado.

A dificuldade para usar esses conceitos reside, naturalmente, na mensuração da capacidade tributária. Uma sugestão para superar esse problema é tomar as médias nacionais na determinação da capacidade tributária das unidades da federação. Nesse caso, a comparação da arrecadação tributária de cada unidade federada com o valor resultante da multiplicação do PIB pela carga tributária nacional forneceria uma medida determinística da eficácia fiscal, tal que:

$$
\begin{aligned}
& \mathrm{R}_{\mathrm{i}, \mathrm{t}}=\mathrm{R}^{*}{ }_{\mathrm{i}, \mathrm{t}} \cdot \mathrm{E}_{\mathrm{i}, \mathrm{t}} \\
& \mathrm{R}_{\mathrm{i}, \mathrm{t}}^{*}=\widetilde{\mathrm{C}}_{\mathrm{i}, \mathrm{t}} \times \mathrm{PIB}_{\mathrm{i}, \mathrm{t}} \\
& \widetilde{C} T_{i, t}=\left(\frac{\widetilde{R}_{i, t}}{P I B_{i, t}}\right)
\end{aligned}
$$

em que:

$\mathrm{R}_{\mathrm{i}}^{\mathrm{t}}=$ arrecadação tributária efetiva da unidade de governo i no período $\mathrm{t}$,

$\mathrm{R}_{\mathrm{i}, \mathrm{t}}^{*}=$ capacidade tributária potencial da unidade federada i no período $\mathrm{t}$,

$\mathbf{E}_{\mathrm{i}, \mathrm{t}}=$ esforço fiscal de arrecadação da unidade de governo i no período $\mathrm{t}$,

$\mathrm{R}_{\mathrm{i}, \mathrm{t}}^{*}=$ arrecadação tributária potencial da unidade federada i no período $\mathrm{t}$, $\widetilde{\mathrm{C}} \mathrm{T}_{\mathrm{t}}=$ carga tributária nacional no período t, $\widetilde{\mathrm{C}}_{\mathbf{t}}=$ arrecadação tributária nacional no período $\mathrm{t}$,

$\mathrm{PIB}_{\mathrm{i}, \mathrm{t}}=$ produto interno bruto da unidade federativa i no período t e $\mathrm{PI}_{\mathrm{t}}=$ produto interno bruto nacional no período $\mathrm{t}$.

Da equação (1) pode-se deduzir que há uma diferença entre a capacidade tributária - que diz respeito à arrecadação tributária máxima que se poderia obter, dadas as características econômicas de uma determinada jurisdição - e a arrecadação tributária - que se refere à arrecadação efetiva obtida nessa mesma jurisdição. Pela mesma equação (1), nota-se que a arrecadação efetiva (ATi,t) depende do esforço fiscal 
(Ei,t) do órgão responsável pela arrecadação. Sendo assim, a arrecadação efetiva é igual à arrecadação potencial (AT $\left.{ }^{*} \mathrm{i}, \mathrm{t}\right)$ sempre que Ei,t $=1$. Caso contrário, a arrecadação tributária efetiva aumenta quando Ei,t > 1. Há ainda outros métodos determinísticos para mensurar a capacidade tributária baseada na composição tributária, porém todos superestimam ou subestimam a capacidade tributária potencial das unidades federativas que possuem estruturas econômicas e de arrecadação diferentes (WILDASIN, 1987, p. 123-145; COSSÍO, 1998, p. 52-53).

\subsection{Modelo econométrico de mensuração da capacidade de arrecadação}

Outra maneira de determinar a capacidade fiscal de um estado da federação consiste na adoção de modelos econométricos capazes de estimar a função de arrecadação tributária nacional e, a partir dela, determinar a capacidade de arrecadação tributária potencial de cada unidade federativa com base nos coeficientes médios estimados das variáveis explicativas da arrecadação tributária nacional. Na verdade, o método econométrico de "fronteira estocástica" que será aqui usado é uma adaptação do método de estimação da função de produção agrícola desenvolvido, entre outros, por BATTESE (1992), BATTESE;TESSEMA (1993), BATTESE: COELI (1995) e BATTESE; MALIK; GILL (1996).

Por analogia ao conceito de fronteira tecnológica de produção agrícola, a fronteira estocástica de arrecadação tributária potencial ou capacidade tributária potencial é definida como o máximo de arrecadação tributária que uma unidade federada pode obter dada sua base e sua estrutura tributária. A metodologia adotada permite diferenciar os dois componentes da equação da arrecadação tributária: a capacidade tributária potencial das unidades federadas e o esforço fiscal de arrecadação dos governos da União, dos estados e dos municípios. Duas são as vantagens que justificam a utilização do método de fronteira estocástica para fins de mensuração da capacidade de arrecadação potencial de uma dada unidade federada: a primeira diz respeito à compatibilização entre a capacidade tributária potencial e a estimação econométrica do valor máximo de arrecadação tributária; a segunda refere-se à comparação entre as arrecadações efetiva e potencial, que permite medir a eficiência tributária nas três esferas de governo nas distintas unidades federativas. De acordo com COSSÍO (1998, p. 5456), o primeiro passo à estimação é a especificação da função de arrecadação a ser estimada, de modo que

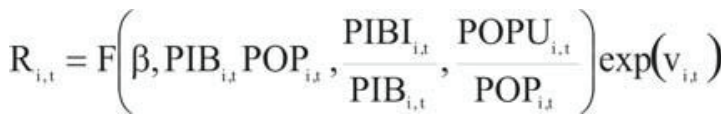

$$
\begin{aligned}
& \text { em que: }
\end{aligned}
$$

$\mathbf{R}_{\mathbf{i}, \mathrm{t}}=$ arrecadação tributária efetiva na unidade federada i no período $\mathrm{t}$, 
PIB $_{\mathrm{i}, \mathrm{t}}=$ produto interno bruto na unidade federativa i no período $\mathrm{t}$, $\mathrm{PIBI}_{\mathrm{i}, \mathrm{t}}=$ produto interno bruto industrial na unidade federada i no período $\mathrm{t}$, $\mathrm{POP}_{\mathrm{i}, \mathrm{t}}=$ população total na unidade federada i no período $\mathrm{t}$,

POPU $_{i, t}=$ população urbana na unidade federada i no período t e $\mathrm{v}_{\mathrm{i}, \mathrm{t}} \quad=$ termo de erro.

Neste ponto, cabe introduzir a especificação do termo de erro, $\mathrm{r}_{\mathrm{i}, \mathrm{t}^{\prime}}$ como a principal inovação do método de fronteira estocástica, pois o resíduo composto $\mathrm{v}_{\mathrm{i}, \mathrm{t}}$ pode ser assim definido:

$\mathrm{v}_{\mathrm{i}, \mathrm{t}}=\mathrm{u}_{\mathrm{i}, \mathrm{t}-} \mathrm{e}_{\mathrm{i}, \mathrm{t}}$

em que

$$
\begin{aligned}
& u_{i}^{\prime}=\text { i.i.d } N\left(0, \sigma_{u}^{2}\right) \text { e } \\
& u_{i}^{\prime}=\text { i.i.d } N\left(0, \sigma_{u}^{2}\right) .
\end{aligned}
$$

Isso significa que o termo de erro, $\mathbf{v}_{\mathbf{i}^{\prime}}^{\mathbf{t}}$ pode ser desdobrado em dois: 1) o termo de erro $\mathbf{u}_{\mathrm{i}^{\prime}}^{\mathrm{t}}$ do tipo estocástico, que pode estar associado a efeitos das políticas não tributárias que afetam o nível da arrecadação tributação, como os incentivos fiscais, as guerras fiscais, as sonegações e isenções e outros; 2) o termo de erro $\mathbf{e}_{\mathbf{i}^{\prime}}^{\mathbf{t}}$ talvez "menos estocástico", que pode estar associado às condições específicas do esforço fiscal das administrações tributárias de cada jurisdição.

A especificação do termo de erro estocástico, $\mathbf{v}_{\mathbf{i}^{\prime}}^{\mathbf{t}}$ implica que a diferença entre a capacidade tributária potencial (arrecadação tributária potencial) e a arrecadação tributária efetiva é dada pelo componente estocástico $\mathbf{e}_{\mathrm{i}}^{\mathrm{t}}$. Nessa condição, a capacidade tributária potencial da unidade federativa i no tempo $t, R_{i, t}^{*}$ pode ser assim definida:

$\mathrm{R}_{\mathrm{i}, \mathrm{t}}^{*}=\mathrm{F}\left(\beta, \mathrm{PIB}_{\mathrm{i}, \mathrm{t}}, \mathrm{POP}_{\mathrm{i}, \mathrm{t}}, \frac{\operatorname{PIBI}_{\mathrm{i}, \mathrm{t}}}{\mathrm{PIB}_{\mathrm{i}, \mathrm{t}}}, \frac{\operatorname{POPU}_{\mathrm{i}, \mathrm{t}}}{\operatorname{POP}_{\mathrm{i}, \mathrm{t}}}\right) \exp \left(\mathrm{u}_{\mathrm{i}, \mathrm{t}}\right)$

O esforço fiscal pode ser assim obtido pela razão entre a arrecadação tributária efetiva e a arrecadação tributária potencial, tal que:

$E_{i, t}=\frac{R_{i, t}}{R_{i, t}^{*}}$ 
Substituindo (4) e (6) em (7), tem-se:

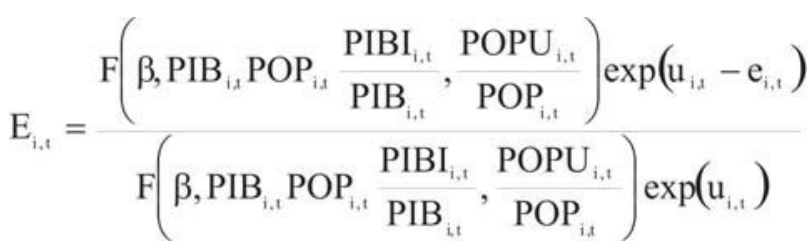

$\mathrm{E}_{\mathrm{i}, \mathrm{t}}=\exp \left(-\mathbf{e}_{\mathrm{i}, \mathrm{t}}\right)$

Considerando que os termos de erros $\mathbf{e}_{\mathbf{i}, \mathrm{t}}$ sejam não-negativos, ou seja, que o esforço fiscal não possa ser negativo, pode-se inferir que $\mathrm{R}_{\mathrm{i}, \mathrm{t}}<\mathrm{R}_{\mathrm{i}, \mathrm{t}^{\prime}}^{*}$ isto é, a capacidade de tributária potencial é o limite superior ou a fronteira estocástica da arrecadação tributária. O nível de eficiência técnica média (ETmédia) é calculado pela seguinte fórmula:

$$
\begin{aligned}
\mathrm{ET}_{\text {média }} & =2\left[1-\mathrm{F}\left(\sigma_{\mathrm{u}}\right)\right] \exp \left(\frac{1}{2} \sigma_{u}^{2}\right), \\
& \text { em que } \mathrm{F}\left(\sigma_{\mathrm{u}}\right) \text { é dado pela tabela de Greene (1997). }
\end{aligned}
$$

\subsubsection{Fontes de dados e definição das variáveis}

No Brasil, os pioneiros na utilização do modelo de fronteira estocástica aplicada ao campo das finanças públicas foram REIS; BLANCO (1996) e COSSÍO (1998). Em ambos, percebe-se uma preocupação com a necessidade de mensurar o esforço fiscal das três esferas de governo, no período de taxa de inflação alta, o que implicaria a necessidade de aumento da carga tributária na ausência de crescimento econômico e alguma mudança na base tributária. O modelo de fronteira estocástica foi também usado por RIBEIRO (1998) para estudar a relação entre a capacidade tributária potencial, as transferências intergovernamentais e o esforço fiscal dos estados brasileiros entre os anos de 1985 e 1995. AFONSO et all (1998) também realizou estudo para medir o esforço fiscal e a capacidade tributária dos estados do Brasil entre os anos de 1990 a 1996. AFONSO; RESENDE; SILVA; VARSANO (1989) realizaram um estudo com o objetivo de medir o esforço tributário e a capacidade tributária da economia brasileira comparativamente a 27 países para o período de 1991 a 1996. Todos eles utilizaram o software Frontier 2.0 para estimar os coeficientes das variáveis e as estatísticas lambda e sigma.

Neste trabalho, usou-se o software LIMDEP 8.0, que já possui uma rotina apropriada para a estimação de funções de fronteira estocástica, o que facilitou muito o trabalho. Estando corretas a entrada dos dados e as informações da rotina, o programa emite as estimativas dos parâmetros por MV da função da fronteira estocástica (CONCEIÇÃO, 2004; GREENE, 1990, 1991). Neste momento, testar-se-á se o modelo de fronteira é ou não adequado por meio da análise dos valores, sinais e 
testes dos parâmetros das variáveis e das estatísticas - lambda e sigma. O modelo formulado foi adotado para a arrecadação tributária dos estados do Brasil. Foram tomados os dados na forma de painel para os 26 estados e o Distrito Federal nos anos censitários de 1970, 1975, 1980, 1985, 1990, 1995 e 2000. No entanto, cabe observar que o interesse maior deste artigo é a mensuração da capacidade de arrecadação tributária potencial e da arrecadação tributária efetiva dos estados da Amazônia para computar o esforço fiscal.

Reconhece-se que a inclusão de outras variáveis referentes à distribuição de renda, ao mercado informal e às exportações líquidas poderia melhorar a determinação da capacidade tributária dos estados. Contudo, as variáveis explanatórias especificadas neste modelo de fronteira estocástico têm sido as mais utilizadas nos estudos de mensuração da capacidade tributária e do esforço fiscal. Para caracterizar a base tributária do modelo, foram usadas as seguintes variáveis: o produto interno bruto (PIB) brasileiro e a população total (POP) como determinantes básicos; a participação do produto industrial (PIBI_PIB) no PIB, para captar a influência do grau de industrialização sobre a base tributária dos estados; a participação da população urbana na população total (POPU_POP), para captar o efeito do grau de urbanização na arrecadação tributária estadual. Por fim, incorporou-se a taxa de inflação (INF) brasileira, para captar seus efeitos sobre a arrecadação dos estados. ${ }^{1}$

O modelo de fronteira estocástico foi adotado somente para a arrecadação tributária dos estados federados brasileiros. Os dados sobre a arrecadação tributária foram obtidos na Secretaria do Tesouro Nacional (STN) e na Secretaria da Receita Federal (SRF) do Ministério da Fazenda (MF); os dados sobre o produto interno bruto e o produto industrial foram obtidos no banco de dados do Instituto de Pesquisa Econômica Aplicada (IPEA) e do IBGE. Os valores nominais foram todos deflacionados a preços de 2000 pelo IGP-DI da Fundação Getúlio Vargas (FGV). Utilizou-se a especificação duplo-logarítmica do modelo econométrico de fronteira estocástica para facilitar a interpretação dos coeficientes obtidos das variáveis consideradas, de modo que:

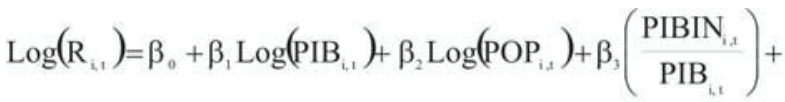

$$
\begin{aligned}
& \beta_{4}\left(\frac{\operatorname{POPUV}_{i}}{\operatorname{POP}_{i, t}}\right)+\beta_{5} \log \left(\mathbb{I N F}_{i, t}\right)+\mathrm{v}_{\mathrm{it}}
\end{aligned}
$$

\footnotetext{
${ }^{1}$ É evidente que o modelo de fronteira estocástica ressente-se da inclusão de outras variáveis, como a distribuição da renda e das exportações, que permitiriam mensurar também a importância dos incentivos fiscais. Além disso, poder-se-ia acrescentar uma variável proxy para captar a influência dos fatores estruturais associados à evasão fiscal, tendo como indicador o grau de formalização do mercado de trabalho.
} 
David Ferreira Carvalho / Cléo C. Resque de Oliveira / André Cutrim Carvalho.

\subsection{Análise dos resultados}

Com a utilização do programa LIMDEP 8.0, foram obtidas as estimativas dos parâmetros por máxima verossimilhança (MV) da equação do modelo 10, além das estatísticas lambda e sigma, como apresenta a Tabela 10. Note-se que a Tabela 10 emite os resultados da função média computada por meio de MQO e depois por MV. Os parâmetros estimados da função média são significativos a 1\%, com exceção do grau de industrialização e da taxa de inflação. O teste F é significativo a 1\%, o que confirma a escolha das variáveis explicativas como representativas do modelo. O coeficiente de determinação de 0,72 é satisfatório, já que outras variáveis explicativas importantes deixaram de ser incluídas.

Tabela 10: Estimativas por máxima verossimilhança dos parâmetros da equação de capacidade tributária dos estados do Brasil. (Variável dependente: arrecadação tributária).

\begin{tabular}{|l|c|c|}
\hline \multicolumn{1}{|c|}{ Itens } & Função média & Função estocástica \\
\hline \multirow{2}{*}{ Constante } & $-1,1651$ & $-1,1378$ \\
& $(-2,333)$ & $(-0,250)$ \\
\hline \multirow{2}{*}{ PIB } & 0,5416 & 0,5569 \\
& $-5,4520$ & $-5,7450$ \\
\hline \multirow{2}{*}{ POP } & 0,8836 & 0,7910 \\
& $-7,8910$ & $-6,7360$ \\
\hline PIBI_PIB & $-0,2770$ & $-0,2428$ \\
& $(-1,509)$ & $(-1,606)$ \\
\hline POPU_POP & 0,4609 & 0,3809 \\
& $-3,1440$ & $-2,9170$ \\
\hline INF & $-0,0404$ & $-0,0456$ \\
& $(-0,753)$ & $(-0,682)$ \\
\hline $\mathrm{R}^{2}$ & 0,7200 & - \\
\hline$\chi^{2}$ & 242,99 & - \\
\hline Teste F(5,183) & 95,79 & - \\
\hline \multirow{2}{*}{ Lambda $(\lambda)$} & & 1,3754 \\
& & $-3,4680$ \\
\hline Sigma $(\sigma)$ & & 1,5526 \\
\hline \multirow{2}{*}{ Gama $(\gamma)$} & & $-13,46$ \\
\hline$\sigma$ & & 0,6543 \\
\hline$\sigma_{v}^{2}$ & & 1,1982 \\
\hline$\sigma_{u}^{2}$ & & 0,8336 \\
\hline LFMV & & 1,5770 \\
\hline UFs & & $-298,99$ \\
\hline Períodos & & 27,00 \\
\hline Observacões & & 7,00 \\
\hline Iteraços & & 189,00 \\
\hline & & 16,00 \\
\hline & & \\
\hline & & \\
\hline
\end{tabular}


O teste qui-quadrado confirma o bom ajuste, a julgar pelo seu valor superior ao valor crítico de sua distribuição. Os testes t dos parâmetros das variáveis básicas são robustos, com exceção da variável que capta o grau de industrialização e da taxa de inflação. No modelo de fronteira estocástica, os testes de hipóteses sobre os parâmetros $\sigma_{u}^{2}, \sigma_{v}^{2}, \sigma^{2}$ e $\gamma$ permitem determinar a) se o método de estimação de fronteira estocástica é adequado para o problema que está sendo estudado e b) se a eficiência da arrecadação tributária tende a melhorar com o tempo. A adequação ou não do método de fronteira estocástica depende da participação da variância estocástica $\left(\sigma_{u}^{2}\right)$ na variância total do modelo especificado $\left(\sigma_{\mathrm{v}}^{2}=\sigma_{\mathrm{u}}^{2}+\sigma^{2}\right)$. O critério de tal avaliação é baseado na interpretação do valor assumido pelo parâmetro $\left(\lambda=\delta_{u} / \delta_{v}\right)$.

No modelo estimado, $\lambda=1,3754$ é estatisticamente significativo a $1 \%$, o que implica que o termo de erro u é dominante em relação ao termo de erro v. Isso significa que a diferença entre a arrecadação efetiva e a arrecadação potencial deve-se principalmente à presença de ineficiência. Por sua vez, o efeito da ineficiência técnica na variação da arrecadação tributária efetiva pode ser capturado pelo valor do parâmetro $\gamma=\frac{\sigma_{u}^{2}}{\sigma^{2}}$. No presente estudo, $\gamma=0,6543$ significa que 65,43\% da variação da arrecadação deve-se à ineficiência técnica.

Os demais resultados, conforme a Tabela 10, confirmam o ajuste do modelo formulado a partir dos fatores determinantes da base tributária para a arrecadação tributária dos estados brasileiros. De fato, o ajustamento do modelo de fronteira estocástica é bastante satisfatório, como se pode constatar pelo valor da função de máxima verossimilhança, FMV = - 298,99, e também pelo nível de significância da maioria dos coeficientes. Os valores dos parâmetros estimados das variáveis definidoras da base tributária dos estados brasileiros são quase todos significativos em nível de 1\% de probabilidade de erro.

\subsubsection{Análise das estimativas dos parâmetros}

As variáveis econômicas e demográficas do modelo de fronteira estocástico ajustado são importantes na determinação da capacidade tributária estadual. Porém, a variável que capta a influência do grau de industrialização apresenta, surpreendentemente, um efeito negativo sobre a arrecadação tributária dos estados. Esse fato resulta, provavelmente, de distorções no âmbito da arrecadação tributária estadual, em decorrência da política de concessão de incentivos fiscais para a indústria, da guerra fiscal, da desoneração tributária das exportações e da evasão fiscal, em conseqüência do crescente aumento da economia informal. 
É provável que a pressão da cobrança de contribuições para-fiscais sobre o setor industrial tenha também contribuído para a perda da capacidade de arrecadação tributária dos estados, não só por causa da estratégia empresarial de busca da integração vertical - para fugir aos efeitos dos tributos em cascatas -, como também por desinteresse dos governos estaduais de um maior esforço fiscal para aumentar a arrecadação tributária própria, devido à garantia constitucional de financiamento parcial por meio das transferências intergovernamentais, o que acaba gerando certa acomodação fiscal (COSSÍO, 1998, p. 60).

A participação do produto industrial no PIB estadual - que procura mensurar o efeito da concentração industrial sobre a arrecadação tributária dos estados - exerce uma influência negativa, porém estatisticamente insignificante. Isso sugere que os fartos incentivos fiscais concedidos pelos governos estaduais às empresas privadas urbanas, em conseqüência da guerra fiscal, podem estar acarretando perdas de arrecadação tributária. O efeito da variável PIB - como medida da capacidade de pagamento dos contribuintes dos estados - determina uma maior capacidade da arrecadação tributária estadual. De fato, o sinal positivo do parâmetro estimado do PIB na tributação estadual indica que um aumento de $1 \%$ no PIB, tudo o mais constante, aumenta a receita tributária estadual em 0,55\%. Esse efeito do PIB na arrecadação estadual é significativo a $1 \%$ de probabilidade de erro.

A população total também estabelece uma relação positiva com a arrecadação tributária. De fato, o tamanho da população exerce um efeito positivo sobre a arrecadação tributária estadual. Isso significa que um aumento da população causa retornos crescentes da receita tributária estadual. O aumento de 1\% da população aumenta, em média, 0,79\% a arrecadação tributária estadual em nível de significância de 1\%. O grau de urbanização - dado pela participação da população urbana na população total - também afeta a arrecadação tributária estadual. Para cada 1\% de aumento da concentração urbana, há um aumento, em média, de 0,38\% da arrecadação tributária dos estados num nível de significância de 1\%. Isso significa dizer que o aumento da concentração urbana tende a reduzir custos e a facilitar a obtenção das receitas tributária estaduais. Quanto ao efeito da taxa de inflação sobre a arrecadação tributária dos estados, notase que o seu impacto negativo não é estatisticamente significativo, talvez devido ao efeito do Plano Real.

\subsubsection{Análise do esforço fiscal}

Os resultados das estimativas apresentadas na Tabela 10 permitem também que se quantifique a capacidade de arrecadação tributária potencial, a arrecadação tributária efetiva e, por conseguinte, o esforço fiscal das unidades governamentais por cada unidade federativa. Nesse 
aspecto, como já foi dito, a diferença entre a desigualdade da arrecadação tributária efetiva e a capacidade tributária potencial dentro de cada nível de governo permite inferir que, além dos componentes estruturais - produto interno bruto, população, grau de industrialização e urbanização, entre outros -, a diferença quanto ao grau de eficiência fiscal na exploração das bases tributárias pelas unidades de governo constitui o outro componente importante na determinação das desigualdades inter-regionais da arrecadação tributária per capita. Nesse sentido, uma segunda vantagem do modelo de estimação por meio da fronteira estocástica da arrecadação tributária é permitir avaliar o esforço fiscal dos diferentes governos estaduais, comparando-se a arrecadação tributária efetiva e a capacidade de arrecadação tributária potencial.

Já foi dito que a importância das diferenças no grau de eficiência fiscal depende da relação entre a variância total $\left(\sigma_{v}^{2}\right)$ do modelo e a variância atribuída à eficiência fiscal dos estados $\left(\sigma^{2}\right)$. No estudo em questão, a Tabela 10 mostra que $\lambda=1,3754$ é significativamente diferente de zero a $1 \%$ de probabilidade de erro para todas as estimações efetuadas, o que sugere que as diferenças existentes no grau de eficiência fiscal, com que os governos estaduais arrecadam tributos nas suas respectivas unidades federadas, constituem um fator importante para explicar as diferenças inter-estaduais na arrecadação tributária. O grau de ineficiência técnica da variação da arrecadação tributária efetiva de todos os estados é dada por $\lambda=0,80$, o que significa que $80 \%$ da variação na arrecadação observada devem-se à ineficiência técnica do aparelho fiscal. A eficiência fiscal média é de 50,87\%.

Uma vez estimada a função da capacidade de arrecadação tributária potencial e a estimativa do termo de erro $\mathrm{u}$, com base na metodologia desenvolvida por JONDROW; LOVELL; MATEROV; SCHIMIDT (1982), foi possível calcular a medida de eficiência técnica fiscal de cada estado da federação e também a eficiência técnica fiscal média. Na Tabela 10 estão os resultados do esforço fiscal dos estados brasileiros, inclusive dos estados da Amazônia, calculados a partir dos resíduos de cada estado fornecidos pelo software Limdep versão 8. A distribuição dos estados segundo o esforço fiscal permite inferir padrões tributários compatíveis com o grau de desenvolvimento econômico das regiões e estados. Na Tabela 11, nota-se que, entre 1970 e 1990, os estados das regiões Sul e Sudeste tiveram um elevado esforço fiscal, com exceção do Estado do Rio de Janeiro. Em contrapartida, os estados das regiões Norte e Nordeste apresentaram baixos índices de esforço fiscal, com exceção do Estado do Amazonas. Os estados da região Centro-Oeste apresentam altos índices de esforço fiscal, com exceção do Distrito Federal, talvez pela sua posição político-administrativa. 
Tabela 11: Esforço fiscal dos estados brasileiros: 1970-2000.

\begin{tabular}{crrrrrrrr|r}
\hline Unid.federadas & \multicolumn{1}{|c|}{1970} & \multicolumn{1}{c}{1975} & \multicolumn{1}{c}{1980} & \multicolumn{1}{c}{1985} & 1990 & 1995 & \multicolumn{1}{c}{2000} \\
\hline AC & 0,6027 & 0,5749 & 0,5543 & 0,5135 & 0,5017 & 0,6537 & 0,7527 \\
AL & 0,8786 & 0,8684 & 0,8465 & 0,8271 & 0,7945 & 0,7954 & 0,8067 \\
AM & 0,9316 & 0,9304 & 0,9275 & 0,9152 & 0,9067 & 0,9159 & 0,9227 \\
AP & 0 & 0 & 0 & 0 & 0,5213 & 0,6648 & 0,7665 \\
BA & 0,7572 & 0,7497 & 0,7327 & 0,7076 & 0,7069 & 0,7407 & 0,8167 \\
CE & 0,7516 & 0,7448 & 0,7407 & 0,7318 & 0,7261 & 0,7471 & 0,8008 \\
DF & 0,647 & 0,6446 & 0,6497 & 0,6361 & 0,6317 & 0,6767 & 0,7501 \\
ES & 0,8623 & 0,8529 & 0,844 & 0,8324 & 0,7984 & 0,8061 & 0,8109 \\
GO & 0,8512 & 0,8406 & 0,8342 & 0,7859 & 0,7735 & 0,8136 & 0,8218 \\
MA & 0,6796 & 0,6645 & 0,6305 & 0,6299 & 0,5906 & 0,7776 & 0,7998 \\
MG & 0,7963 & 0,7868 & 0,7801 & 0,7677 & 0,7576 & 0,7783 & 0,8103 \\
MS & 0 & 0 & 0,9164 & 0,9026 & 0,8795 & 0,8994 & 0,9125 \\
MT & 0,9295 & 0,923 & 0,9122 & 0,9038 & 0,8848 & 0,8966 & 0,9245 \\
PA & 0,7385 & 0,7399 & 0,7259 & 0,7102 & 0,7065 & 0,7716 & 0,9099 \\
PB & 0,7444 & 0,7114 & 0,6967 & 0,6586 & 0,6462 & 0,7903 & 0,7955 \\
PE & 0,8 & 0,7765 & 0,7717 & 0,7314 & 0,7136 & 0,7181 & 0,8094 \\
PI & 0,7379 & 0,7201 & 0,6916 & 0,6553 & 0,6355 & 0,6846 & 0,7859 \\
PR & 0,8524 & 0,8409 & 0,8285 & 0,8242 & 0,7986 & 0,8531 & 0,9485 \\
RJ & 0,7259 & 0,7244 & 0,7234 & 0,715 & 0,7112 & 0,7679 & 0,8092 \\
RN & 0,7226 & 0,7218 & 0,7169 & 0,7111 & 0,7038 & 0,7383 & 0,7947 \\
RO & 0 & 0 & 0 & 0,7619 & 0,7527 & 0,7856 & 0,8088 \\
RR & 0 & 0 & 0 & 0,7326 & 0,7225 & 0,7963 & 0,7963 \\
RS & 0,9165 & 0,9112 & 0,8983 & 0,8902 & 0,8838 & 0,8894 & 0,9205 \\
SC & 0,9657 & 0,9599 & 0,96 & 0,9489 & 0,9433 & 0,9496 & 0,954 \\
SE & 0,8289 & 0,8136 & 0,7885 & 0,7648 & 0,7483 & 0,7622 & 0,8093 \\
SP & 0,889 & 0,8774 & 0,8571 & 0,8378 & 0,8273 & 0,8639 & 0,9589 \\
TO & 0 & 0 & 0 & 0 & 0 & 0,8457 & 0,858 \\
\hline BR (média) & 0,6522 & 0,6436 & 0,6677 & 0,7072 & 0,7136 & 0,7919 & 0,8391 \\
\hline & & & & & & &
\end{tabular}

Fonte: Elaboração própria.

Entre 1995 e 2000, portanto depois do Plano Real, nota-se uma melhoria dos índices de esforço fiscal de todos os estados brasileiros, se comparados com os esforços fiscais de 1985-1990 ocorridos num ambiente de alta inflação. Os diferenciais no grau de eficácia tributária entre os estados tornam-se mais brandos. Entre 1995 e 2000, os estados das regiões Sul, Sudeste e Centro-Oeste mantiveram um bom desempenho, captado pelos elevados índices de esforço fiscal; já os estados das regiões Norte e Nordeste melhoraram seus desempenhos, quando medidos os índices de esforço fiscal.

De fato, no caso dos estados da Amazônia, entre 1995 e 2000, o esforço fiscal dos estados do Amazonas, Pará, Rondônia e Tocantins ficaram acima da média do Brasil, mas os estados do Acre, Amapá e Roraima não tiveram o mesmo desempenho, como revela a Tabela 11. Na região Norte, apesar da baixa capacidade de arrecadação tributária dos estados, tal situação não inibiu o forte esforço fiscal, em particular dos estados do Amazonas e Pará. 


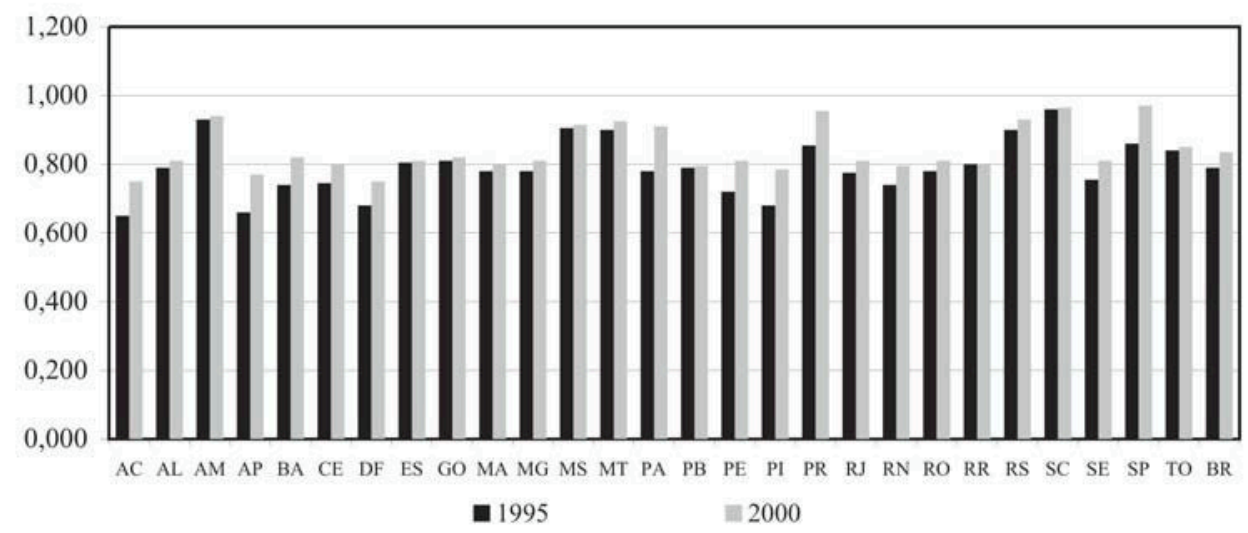

Gráfico 1: Esforço fiscal dos estados brasileiros: 1995-2000.

Os diferenciais do grau de esforço fiscal entre estados tornaramse mais suaves no período de estabilidade macroeconômica após o Plano Real, entre 1995 e 2000, se comparado com o período imediatamente anterior, 1985-1990. São Paulo ocupa a posição de liderança no ranking, e o Distrito Federal, a última colocação. Os resultados obtidos sobre o esforço fiscal dos estados brasileiros, entre 1995 e 2000, podem ser observados na Gráfico 1. Constatam-se aí as diferenças existentes no grau de eficácia tributária entre os estados brasileiros. Assim, enquanto os estados de São Paulo, Paraná e Santa Catarina apresentam valores elevados acima de $94 \%$, outros, como a maioria dos estados do Nordeste e do Norte, apesar da melhoria do esforço fiscal, ainda estão aquém de 80\% da capacidade de arrecadação tributária máxima. No caso dos estados da região Norte, houve uma significativa melhora do esforço fiscal de todos os estados, quando se compara a situação com o período de 1985 a 1990, em particular nos estados do Amazonas, Pará e Rondônia, como mostrado na Gráfico 1.

\section{CONCLUSÃO}

Este trabalho visou organizar algumas informações que permitissem associar as fontes das desigualdades tributárias às desigualdades econômicas inter-regionais por unidades federadas estaduais. A baixa capacidade tributária dos estados da periferia acaba contribuindo para o crescente aumento das transferências intergovernamentais. O aumento das transferências intergovernamentais pode causar certa acomodação quanto ao esforço fiscal dos estados da periferia. No período de alta inflação, os estados defendiam-se indexando a cobrança dos impostos. Depois do Plano Real, o programa PNAFE proporcionou uma melhoria tecnológica na administração fiscal dos aparelhos tributários dos estados da periferia. 
O resultado desse programa contribuiu também para a melhoria no grau do esforço fiscal dos estados envolvidos.

Neste trabalho, ficou evidenciada a relação existente entre as disparidades econômicas inter-regionais e as diferenças na arrecadação tributária autônoma dos estados. O problema da transferência vertical de parte da receita tributária de União aos estados da Amazônia tende a agravar-se, pois as receitas tributárias autônomas só irão aumentar substancialmente se houver também mudança na base produtiva dos estados, enquanto as despesas reais tendem a crescer fortemente com a queda da inflação. Porém, a conclusão mais importante é a confirmação das disparidades na eficácia tributária entre os estados federados, em particular nos estados da Amazônia.

É claro que essas disparidades tributárias estão associadas ao grau de industrialização dos estados. Não obstante, as disparidades tributárias mais agudas podem estar refletindo também certa ineficiência na administração tributária de alguns estados da periferia. De fato, a redução da arrecadação tributação efetiva e autônoma - aquém do razoável explicado pelas diferenças da renda per capita - aponta para a necessidade de melhorias na administração tributária, visando o aumento no grau do esforço fiscal dos estados. Por fim, é bom ressaltar que essas conclusões são ainda preliminares, pois não foi possível incorporar a este trabalho os outros importantes fatores estruturais associados à base tributária, como, por exemplo, as atividades informais e as exportações. 


\section{REFERÊNCIAS}

AFONSO, José Roberto. "Transferências intergovernamentais e o funcionamento de estados e municípios". Revista de Finanças Públicas, n. 363, p. 32-41, 1986.

AFONSO, José Roberto et all. "Tributação no Brasil: Características marcantes e diretrizes para a reforma". Revista do BNDES. Rio de Janeiro, BNDES, p. 25-50, 1998.

AFONSO, J. R., REZENDE, F., SILVA, M. C., VARSANO,R. "A tributação e o orçamento na nova Constituição". In: Perspectivas da economia brasileira-1989. Rio de Janeiro, IPEA, p. 585-600, 1989.

AFFONSO, Rui Brito Álvares. "A Federação no Brasil: Impasses e Perspectivas". In: A Federação em Perspectivas: Ensaios Selecionados. Rui de Brito Álvares Affonso \& Pedro Luiz Barros Silva. São Paulo, FUNDAP. 1995.

AGHÓN, Gabriel. "Descentralización fiscal: marco Conceptual". Série Política Fiscal n. 44, CEPAL, Santiago, Chile. 1991.

AIGNER, D. J., LOVELL, C. A., SMITH, D. L. "Formulation and estimation of stochastic frontier production function models. Journal of Econometrics. n. 6, p. 21-37, 1977.

AMED, José Fernando \& NEGREIROS, Plínio José Labriola de Campos. História dos Tributos no Brasil. São Paulo, SNAFRESP. 2000.

ATKINSON, A. \& STIGLITZ, J. Lectures in public economic. New York, MacGraw-Hill. 1980.

BUCHANAN, J. \& BRENANN, G. "Towards a tax constitution for Leviathan". Journal of Public Economics, v. 8, p. 255-273. 1977.

BATTESE, G. "Frontier production functions and technical efficiency: a survey of empirical applications in agricultural economics". Agricultural Economics, v. 7, p. 185-208, 1992.

BATTESE, G.; TESSEMA, G. A. "Estimation of stochastic frontier production with time varying parameters technical efficiencies using panel data from Indian villages". Agricultural Economics, v. 9, p. 313333, 1993.

BATESSE, G. E COELLI, T. J. "A model for technical inefficiency effcts in a stochastic frontier production function for panel data". Journal Econometrics, v. 38, p. 387-399, 1995. 
BATESSE, G. E., MALIK, S. J. \& GILL, M. A. "An investigation of technical inefficiencies of production of wheat farmers in four districts of Pakistan". Journal of Agricultural Economics, v.47, n.1, p.37-48, 1996.

CONCEIÇÃO, Júnia Cristina P. R. da. "Estimação e Análise de Fronteira de Produção Estocásticas". In: Métodos Quantitativos em Economia. Maurinho Luiz dos Santos \& Wilson da Cruz Vieira.Viçosa, UFV. 2004.

CARVALHO, David Ferreira. "Globalização, Federalismo Regional e o Desempenho Macroeconômico da Amazônia nos anos 90". In: Ensaios Selecionados da Economia da Amazônia nos Anos 90, Vol. I. David Ferreira Carvalho. (Org.). Belém, UNAMA. 2005.

CARVALHO, David Ferreira. "Integração, Desenvolvimento e Desigualdades na Amazônia nos Anos 90 num contexto de Globalização: uma análise da dinâmica regional à luz do federalismo brasileiro". In: Ensaios Selecionados da Economia da Amazônia nos Anos 90, Vol. I. David Ferreira Carvalho. (Org.). Belém, UNAMA. 2005a.

CAVALCANTI, Eduardo G. \& PRADO, Sérgio. Aspectos da Guerra Fiscal no Brasil. Brasília, IPEA; São Paulo, FUNDAP. 1998.

COSSÍO, Fernando Andrés Blanco. Disparidades Econômicas InterRegionais, Capacidade de Obtenção de Recursos Tributários, Esforço Fiscal e Gasto Público no Federalismo Braseileiro. Rio de Janeiro, BNDES. 1998.

DAIN, Sulamis (1997). "Reforma Tributária: Um tema em Suspenso". Revista Anpec n. 3. Brasília, Anpec. 1997.

FIORI, José Luís. "O Federalismo Diante do Desafio da Globalização". In: A Federação em Perspectivas: Ensaios Selecionados. Rui de Brito Álvares Affonso \& Pedro Luiz Barros Silva. São Paulo, FUNDAP. 1995.

GREENE, W. H. "A gamma-distributed stochastic frontier model". Journal of Econometrics, v. 46, p. 143-163, 1990.

GREENE, W. H. LIMDEP: User's manual and reference guide. New York, Econometric Software. 1991.

GREENE, W. H. Econometric Analysis. New York, Prentice Hall. 1997.

GIAMBIAGI, Fábio \& ALÉM, Ana Cláudia. Finanças Públicas: Teoria e Prática no Brasil. Rio de Janeiro, Campus. 2000.

GIFFONI, F. \& VILLELA, L. "Tributação de renda e do patrimônio". Texto para Discussão Interna, 105. Rio de Janeiro, IPEA. 1987. 
JONDROW J. LOVELL, C. A. K., MATEROV, I. S. e SCHIMIDT, P. "On the estimation of technical inefficiency in the stochastic frontier production function model". Journal of Econometrics, v. 19, p. 233-238, 1982.

KEEN, Michael. "Vertical Tax Externalities in the Theories of Fiscal Federalism". MF Working Paper, WP/97/173. 1977.

KHAIR, Amir antônio. A Questão Fiscal e a Lei de Responsabilidade Fiscal. In: Política Fiscal e Desenvolvimento no Brasil. Márcio Percival Alves Pinto \& Geraldo Biasoto Jr. (Org.). Campinas, UNICAMP. 2006.

LOPREATO, Francisco Luiz Cazeiro. O colapso das finanças públicas estaduais e a crise da federação. São Paulo, UNESP e UNICAMP. 2002.

MENDES, Armando Dias. "O Anúncio de uma Nova Amazônia". In: Amazônia: desenvolvimento e ocupação. José Marcelino M. da Costa. (Ed.). Rio de Janeiro, IPEA/INPES. 1979.

MCKENZIE, R. B. \& STAAF, R. F. "Revenue Sharing and Monopoly government". Public Choise. 33 (3), p. 93-97. 1978.

MINISTÉRIO DA FAZENDA. Modernização Fiscal dos Estados Brasileiros. Brasília, MF. 2006.

MUSGRAVE, Richard A. \& MUSGRAVE, Peggy B. Finanças Públicas:Teoria e Prática. São Paulo, Campus. 1980.

NISKANEN, W. A. "Deficits, governmments spendings and inflation: what is the evidence?" Journal of Monetary Economics. n. 4, p. 591-602, set. 1978.

NUNES, Ricardo da Costa \& NUNES, Selene Peres Peres. "Revenue Sharing: A problem of Federalism in Brazil". Revista de Economia Politica. Vol. 20, n. 4 (80), out-dez. 2000.

OATES, Wallace. Fiscal federalism. New York, Harcourt-BraceJovanovich. 2000.

OLIVEIRA, Fabrício Augusto de. Crise, Reforma e Desordem do Sistema Tributário Nacional. Campinas, UNICAMP. 1995.

PELTZMAN, S.(1992)."Voters as fiscal conservatives". Quartely Journal of Economics.N.57, p.327-361.

PRADO, Sérgio. "Transferências fiscais no Brasil: o lado "esquecido". In: Política Fiscal e Desenvolvimento no Brasil. Márcio Percival Alves Pinto \& Geraldo Biasoto Jr. (Org.). Campinas, UNICAMP. 2006. 
QUADROS, Waldemir Luiz de. "A Tributação Indireta no Brasil". In: Reforma Tributária e Federação. Rui de Britto Álvares Affonso \& Pedro Luiz Barros Silva. (Org.). São Paulo, FUNDAP/UNESP. 1995.

TIEBOUT, Charles. "A pure theory of local expenditures". Journal of Political Economy. N. 64, p. 416-424, 1956.

TORRES, João Camilo de Oliveira. A Formação do Federalismo no Brasil. São Paulo, Ed.Nacional. 1961.

REIS, José Eustáquio \& BLANCO, Fernando A. Capacidade Tributária dos Estados Brasileiros: 1970-1990. Texto para Discussão, N. 404. Brasília, IPEA. 1996.

RESENDE, Fernando. "Federalismo fiscal no Brasil". Revista de Economia Política. v. 15, n. 3 (59), jul-set. 1995.

RESENDE, Fernando. Finanças Públicas. São Paulo, Atlas. 2001.

RIBEIRO, Eduardo Pontual. "Transferências Intergovernamentais e Esforço Fiscal dos Estados Brasileiros". Texto para Discussão. N.98/12. Porto Alegre, UFRS. 1998.

SIQUEIRA, Rosane Bezerra de; NOGUEIRA, José Ricardo \& BARBOSA, Ana Luíza Neves de Holanda . "Teoria da tributação ótima". Economia do Setor Público no Brasil. Ciro Biderman \& Paulo Arvate (Orgs.). Rio de Janeiro, Elsevier. 2004.

RUBINFELD, Daniel. "The Economics of local public sector". In: Handbook of Public Economics. Auerbach, J. \& Feldstein, R. (Eds.). New York, North Holland. 1987.

SHAH, Anwar. "The New Federalism in Brazil". World Bank, Discussion Paper, 124. 1992.

WINNER, Stanley. "Some evidence on the effect of the separation of spending and taxing decisions". Journal of Political Economy. v. 91, p. 126-140. 1983.

VARSANO, Ricardo. "A evolução do sistema tributário brasileiro ao longo do século: anotações e reflexões para futuras reformas". Texto Para Discussão. n. 405. Brasília, IPEA. 1996. 


\section{APÊNDICES}

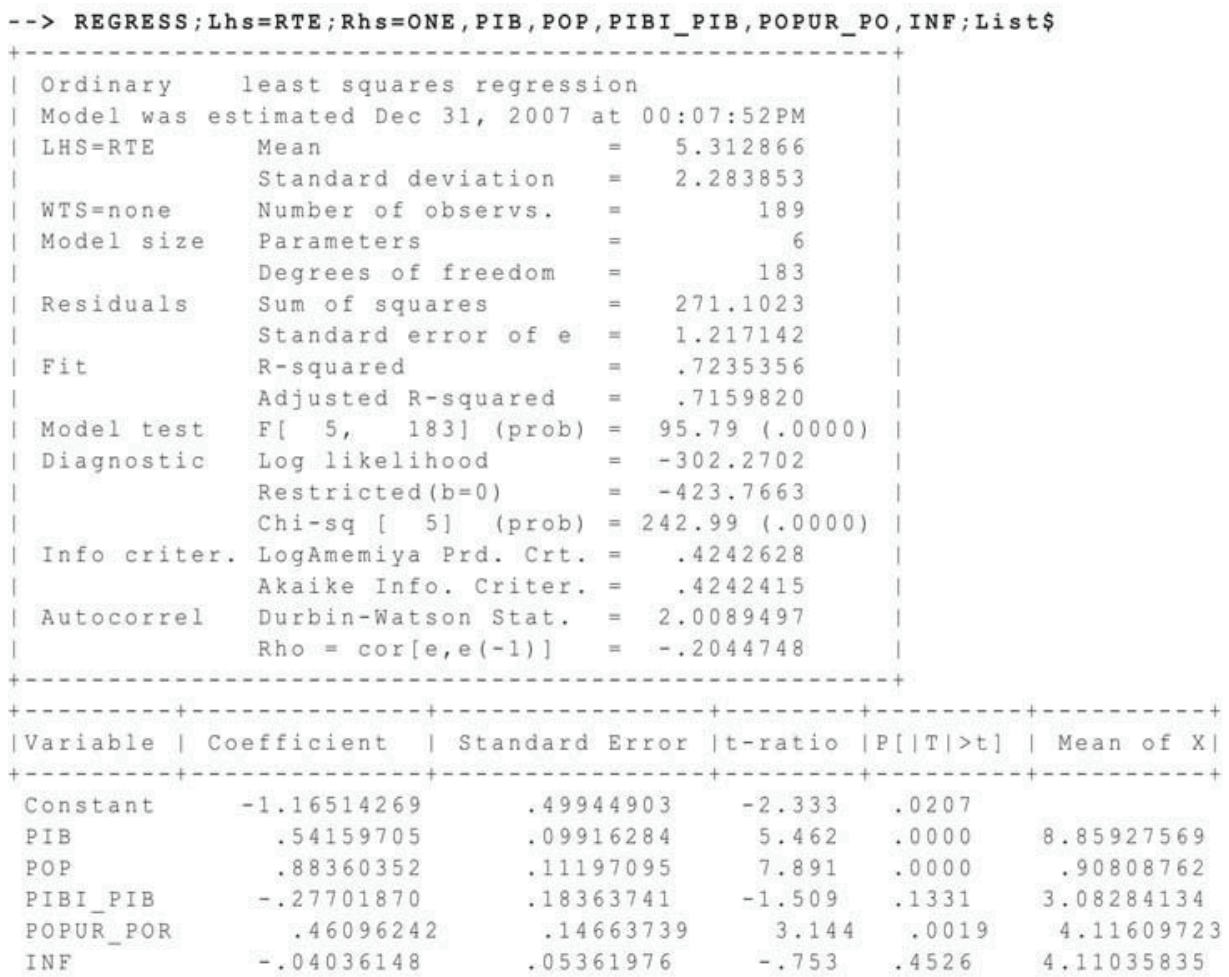

\section{FRONTIER; LhS =RTE; Rhs=ONE, PIB, POP, PIBI_PIB, POPUR_PO, INF; Pds=7\$}

\begin{tabular}{|c|c|c|c|c|c|}
\hline Limited & Dependent Variable & Mode1 - FRONTI & ER I & & \\
\hline Maximum & Likelihood Estimates & & 1 & & \\
\hline Model es & timated: Jan 01, 200 & at $01: 14: 31$ & PM. I & & \\
\hline Dependen & t variable & RTE & 1 & & \\
\hline Weightin & g variable & None & 1 & & \\
\hline Number o & f observations & 189 & 1 & & \\
\hline Iteratio & ns completed & 16 & 1 & & \\
\hline Log $1 \mathrm{ike}$ & 1ihood function & -298.9941 & 1 & & \\
\hline Variance & s: Sigma-squared $(v)=$ & .83361 & 1 & & \\
\hline & sigma-squared $(u)=$ & 1.57705 & 1 & & \\
\hline & $\operatorname{Sigma}(v) \quad=$ & .91302 & 1 & & \\
\hline J & Sigma (u) & 1.25581 & 1 & & \\
\hline Sigma $=$ & $\operatorname{sqr}\left[\left(s^{\wedge} 2(u)+s^{\wedge} 2(v)\right]=\right.$ & 1.55263 & 1 & & \\
\hline Stochast & ic Production Fronti & Ler, $e=v-u$ & 1 & & \\
\hline$--1--1$ & 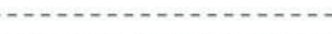 & 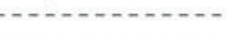 & --++ & & \\
\hline--------1 & 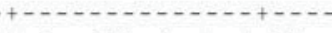 & 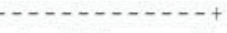 & $-\cdots-\cdots$ & +------ & ++--------+ \\
\hline Variable & I Coefficient | Stan & ndard Error lb & /St.Er. I & $\mathrm{P}[|\mathrm{Z}|>\mathrm{z}]$ & Mean of $\mathrm{X}$ | \\
\hline 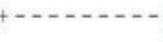 & 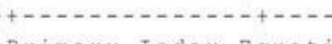 & 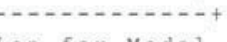 & $\cdots-\cdots+\cdots$ & 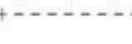 & 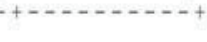 \\
\hline & Primary Index Equati & Lon for Model & & & \\
\hline Constant & .01244894 & .63161567 & .020 & .9843 & \\
\hline P I B & .55688898 & .09693548 & 5.745 & .0000 & 8.85927569 \\
\hline POP & .79104866 & .11743209 & 6.736 & .0000 & .90808762 \\
\hline PIBI_PIB & -.24275669 & .15111242 & -1.606 & .1082 & 3.08284134 \\
\hline POPU_PO & .38098541 & .13060814 & 2.917 & .0035 & 4.11609723 \\
\hline INF & -.04568397 & .06698644 & -.682 & .4952 & 4.11035835 \\
\hline & Variance parameters & for compound & error & & \\
\hline Lambda & 1.37543969 & .39658353 & 3.468 & .0005 & \\
\hline Sigma & 1.55263200 & .11538025 & 13.457 & .0000 & \\
\hline
\end{tabular}

